\title{
Simplified serviceability design of jointless structures. Experimental verification and application to typical bridge and building structures
}

\author{
Giancarlo Groli , Alejandro Pérez Caldentey , Alejandro Giraldo Soto -, Francesco Marchetto , \\ Javier Ezeberry Parrotta
}

Keywords:

Integral structures

Column testing

Imposed deformations

Cracking

Non-linear analysis

\begin{abstract}
A B S T R A C T
In this article an experimental campaign aimed at validating a previously published simplified service ability design method of the columns of long jointless structures is presented. The proposed method is also extended to include tension stiffening effects which proved to be significant in structures with small amount of reinforcement subjected to small axial loading. This extension allows significant improvement of predictions for this type of element. The campaign involved columns with different reinforcement and squashing load ratios, given that these parameters had been identified as crucial when designing columns subjected to imposed displacements. Experimental results are presented and discussed, with particular regard to cracking behaviour and structural stiffness. Considerations on tension stiffening effects are also made. Finally, the application of the method to typical bridge and building cases is presented, showing the feasibility of jointless construction, and the limits which should be respected.
\end{abstract}

\section{Introduction}

When dealing with sustainability in construction, great stress has to be put on the durability of structures. In fact, many RC structures built during the XXth century have failed to show sufficient serviceability standards after few years of construction. One of the reasons for this lack of durability can be found in the use of elastomeric bearings and expansion joints. As already pointed out in [1], their wide use has been based on the idea that it is better to let the structures expand than to resist the forces produced by imposed deformations (temperature, shrinkage, etc.). However, experience has shown that these elements are main culprits in cases of durability problems. Additionally, their cost is often a not negligible part of the cost of the structure.

The growing use of jointless structures has therefore been motivated by the growing concern for durability. Integral structures have been satisfactorily used since the mid XXth century in the US, both for reinforced concrete and composite structures, first in short bridges, and lately reaching remarkable lengths (up to $100 \mathrm{~m}$, as reported in [2]). More recently, the British Department of Transport has published Design for durability documents [3], encouraging the use of jointless structures, and even forbidding midspan joints.

The problem of imposed deformations on concrete structures has been studied by many researchers from the experimental $[4,5]$ and from the theoretical [6-11] points of view. However none of these references include a method which can be easily applied in everyday engineering practice. As a contribution to overcome the difficulties involved in designing the columns of long jointless structures taking into account the non-linearity provided by cracking of RC, a simplified method has been proposed by Pérez et al. [1] and Ezeberry [10].

In order to validate this method and explore other aspects concerning design (such as cracking), a specific experimental campaign has been undertaken. The experimental program involved four columns made of conventional concrete $\left(f_{\mathrm{cm}} \approx 38 \mathrm{MPa}\right)$, conventional reinforcement ( $\mathrm{B}-500$ steel), with different levels of axial force (30\% and $80 \%$ of the squashing load) and reinforcing bar diameters $(012 \mathrm{~mm}$ and $\emptyset 25 \mathrm{~mm}$. These columns were designed to represent a part of a jointless building. The columns were subjected to contemporised action of horizontal and vertical forces from the fictitious structure. The horizontal force was applied by hydraulic jack, whereas the vertical action was simulated by prestress of intemal rebars.

After validation through experimentation, the simplified method mentioned above is used to compile an application guide aimed at providing designers with an order of magnitude of the jointless 


\begin{tabular}{|c|c|c|c|}
\hline \multicolumn{4}{|c|}{ Nomenclature } \\
\hline$\varepsilon_{s}$ & tensile strain of steel & $E_{\mathcal{C}}$ & instantaneous modulus of elasticity of concrete \\
\hline$\varepsilon_{s h}$ & shrinkage strain & $E_{c, \infty}$ & long-term modulus of elasticity of concrete \\
\hline$\varepsilon_{s r}$ & state II analysis strain in steel for the cracking moment & $f_{c d}$ & design compressive strength of concrete \\
\hline$\emptyset$ & bar diameter & $f_{c t}$ & tensile strength of concrete \\
\hline$\Lambda$ & normalized displacement & $h$ & height of the cross section \\
\hline$v$ & squashing load ratio & I & length used for strain measurement $(\mathrm{l}=20 \mathrm{~cm})$ \\
\hline$\chi$ & curvature & $L$ & height of the support \\
\hline$\rho_{s}$ & reinforcement ratio & $k$ & embedment coefficient (ranging from 3 to 6 ) \\
\hline$\rho_{s, \text { eff }}$ & effective reinforcement ratio & $s_{r, m}$ & mean crack spacing \\
\hline$\sigma_{s}$ & stress in the reinforcement at the crack & $s_{r, \max }$ & maximum crack spacing \\
\hline$\sigma_{s r}$ & state II analysis stress in steel for the cracking moment & TS & factor, smaller than 1 , accounting for tension stiffening \\
\hline$b$ & width of the section & $w$ & crack opening \\
\hline$c$ & clear cover of longitudinal reinforcement & $x$ & depth of the neutral axis assuming a fully cracked \\
\hline$d$ & effective depth of reinforcement & & section \\
\hline$E_{s}$ & modulus of elasticity of steel & & \\
\hline
\end{tabular}

lengths which can be achieved for typical applications. The objective of these further investigations is to promote the use of integral structures (buildings or bridges) by removing technical difficulties, and eventually lead to a wider use of this technique, with benefits from the point of view of durability and sustainability of concrete construction.

\section{Simplified method for serviceability design of columns of long jointless structures}

Long-term displacements in RC members may cause delayed damage to the structure itself and other elements. Therefore, they must be accurately estimated at the design stage. The magnitude of the forces acting on the section is significantly affected by the reinforcement ratio and the process can be assessed using a non-linear time-dependent analysis, although this type of analysis requires the selection of a number of parameters, and is computationally demanding.

An easy tool for the approximate evaluation of the reinforcement requirements needed for serviceability conditions in the supports of integral structures has been proposed by Pérez et al. [1]. The method is based on the integration of the moment/curvature law along the support, taking into account the non-linearity generated by the presence of cracked (less stiff) and uncracked (stiffer) regions. By following an iterative procedure, for a given imposed displacement at the support head, the forces acting at the column base are found, and therefore the tension in the reinforcement. As a result a number of curves are obtained, in which the stress in the reinforcement is plotted as a function of a parameter $\Lambda=k \delta d / L^{2}$ (which can be understood as a normalised displacement, since the only variable is imposed displacement $\delta$ ), the reinforcement ratio $\rho=A_{s} / d h$ and the squashing load ratio $v=N /\left(0.85 \cdot b \cdot d \cdot f_{c d}\right)$. In the definition of $\Lambda$, parameter $k$ is the embedment coefficient ranging from 3 (for a cantilever) to 6 (for a doubly embedded column), $d$ is the effective depth of the section and $L$ is the height of the support.

It is worthy to point out that in order to solve in a closed form for rectangular cross-sections the equations governing the moment/curvature relationship (sectional analysis), linear-elastic constitutive laws are used for concrete in compression (neglecting tensile strength) and for steel in both tension and compression. This is justified by considering that, for the force ranges common in the serviceability phase, the concrete behaviour can be regarded as elastic, and Tension Stiffening effects are of limited importance, especially for flexure with significant axial force or high reinforcement ratios. In any case it is shown in this study that these effects are favourable and therefore neglecting them is an approximation to the problem from the safe side.

With this method, which can be applied using charts to simplify the design process, it is possible to operate a non-linear superposition of instantaneous and time-dependent imposed deformations. Long-term effects are taken into account by modifying the Young modulus of concrete and repeating the analysis. This method is known as the effective modulus method (i.e. $E_{c, \infty}=E_{c} / 1+\varphi$, where $\varphi$ is the creep coefficient). Then, instantaneous (e.g. temperature) and long-term effects (e.g. shrinkage) are summed up by the procedure explained in Fig. 1.

The procedure involves the following steps:

- Using a short term curve, determine the stress ratio $\sigma_{s} / \mathbf{f}_{\mathrm{y}}$ from the instantaneous $A$ parameter.

- Using the long term curve, determine the equivalent long term value of $\Lambda, \Lambda_{\infty}$ which would provide the same stress level. Add to this value the increment due to long term strains (shrinkage), $\Delta A_{\infty}$

- Determine the stress level corresponding to $\Lambda_{\infty}+\Delta \Lambda_{\infty}$. This stress corresponds to the sum of short and long term effects. ${ }^{1}$

\section{Experimental program}

\subsection{Test design}

The tests have been designed to fulfil the following criteria and technical limitations:

- The specimens should be representative of real structures.

- The load capacity is limited by the hydraulic jack available which has a maximum capacity of $200 \mathrm{kN}$, and a maximum displacement range of $100 \mathrm{~mm}$. Therefore, the specimens should be designed to develop their full capacity within that range.

- The axial force is be introduced by means of internal prestressed bars, due to the difficulties of keeping a centred vertical force and, at the same time, imposing a displacement at that point using jacks in two directions.

\footnotetext{
${ }^{1}$ Displacement reversals can happen when temperature expansion exceeds shrinkage and creep. Nevertheless, one of the assumptions of the simplified method is that columns are reinforced symmetrically, and the case of displacements reversals is implicitly taken into account. Such effects will therefore have no influence on the analysis when the tensile resistance of concrete is neglected. Displacement reversals, will at most reduce tension stiffening effects, but this can be taken into account in the Tension Stiffening model used to correct the model, if desired.
} 
Relative stress as a function of $k \delta d / L^{2}$ and reinforcement amount ( $\left.p=A_{s} / b d\right)$ $\mathrm{N} /\left(\mathrm{b} \times \mathrm{d} \times \mathrm{f}_{\mathrm{c}}\right)=0.5$

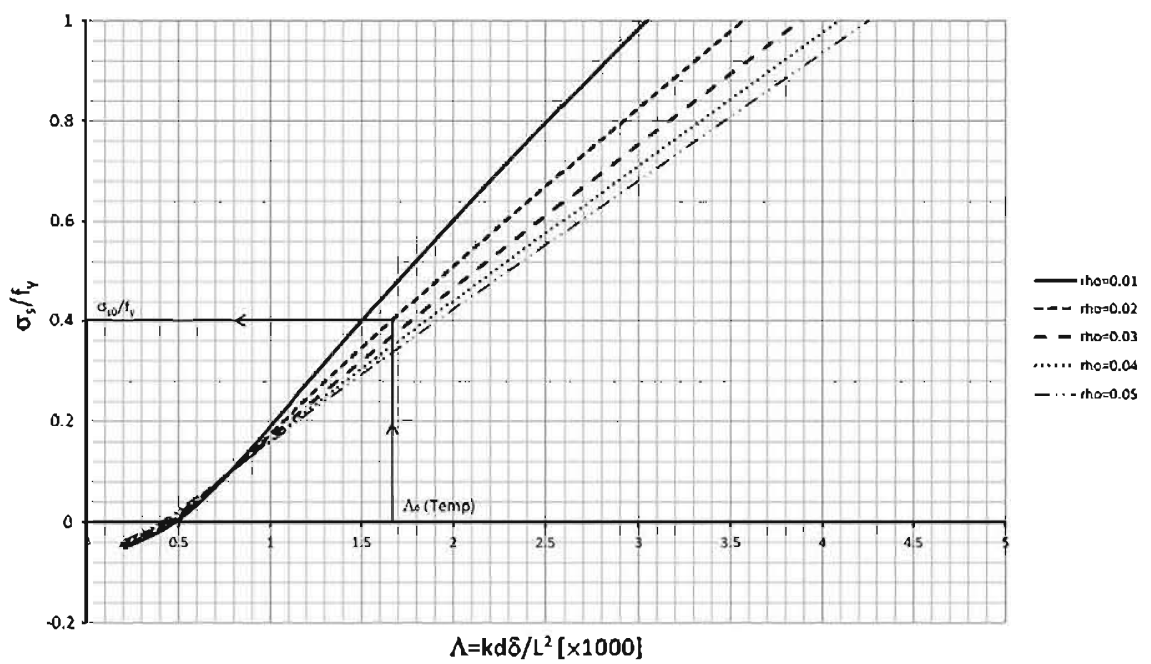

(a)

Relative stress as a function of $k \delta d / L^{2}$ and reinforcement amount $\left(\rho=A_{s} / b d\right)$ $\mathrm{N} /\left(\mathrm{b} \times d \times f_{c}\right)=0.5$ - Time-dependent deformations

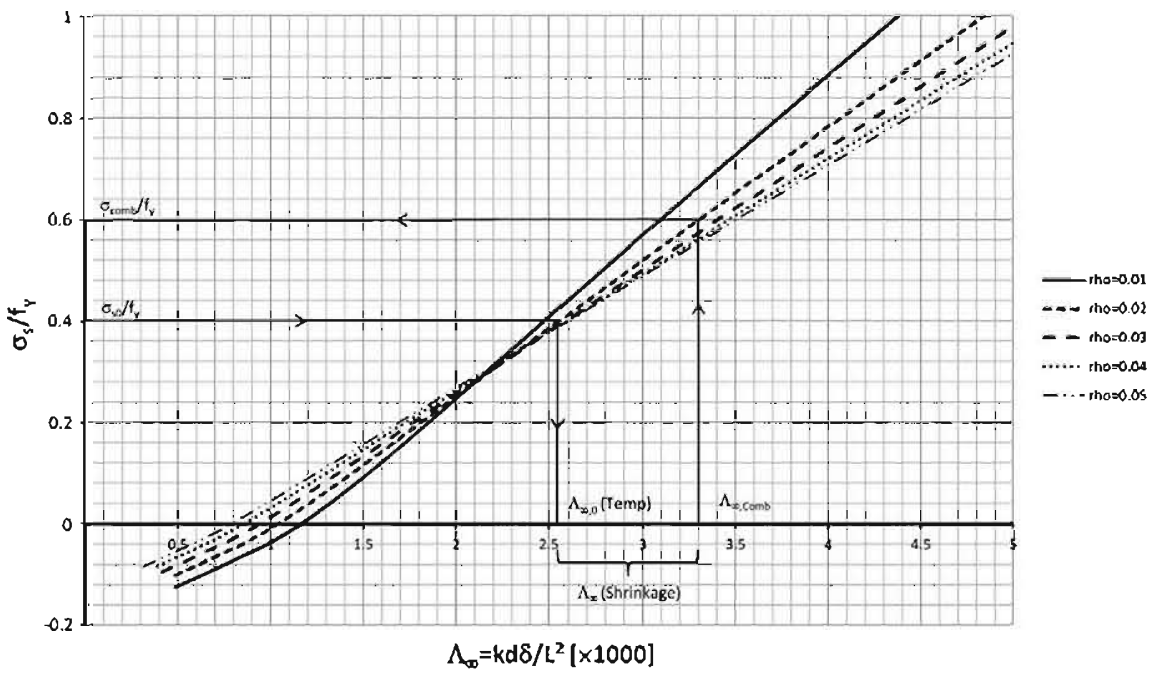

(b)

Fig. 1. Procedure to obtain instantaneous (a) and long-term (b) tension in rebars (from [1]).

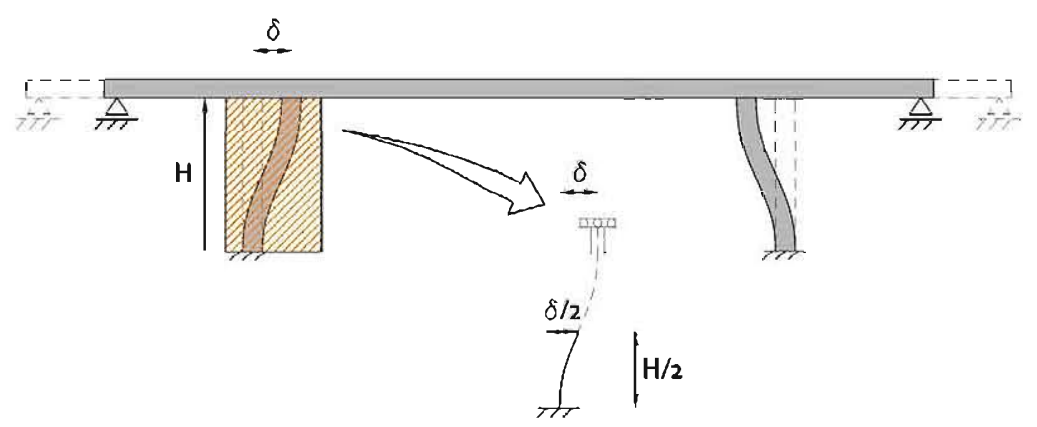

Fig. 2. Structural scheme of specimens and its equivalence in a typical structurc.

It was decided to adopt a cantilever scheme. It can be stated that in a real integral structure this would represent half of a doubly embedded column, with an imposed displacement at the head equal to twice that imposed in the test, as shown in Fig. 2. Given a $30 \times 30 \mathrm{~cm}$ cross section, the height of the column was designed to achieve the full yielding given the maximum force available in the 
jack, so that the serviceability zone could be fully explored. The scheme of the tested column is shown in Fig. 3.

The axial force is provided by prestressed high-strength steel rebars $\left(f_{p y} / f_{p u}=835 / 1050 \mathrm{MPa}\right)$, anchored at the foundation and stressed from the top. In order to avoid friction effects between the prestressing bar and the duct which would be difficult to estimate, the ducts were grouted. This means that prestressing rebars have to be regarded not only as an axial force, but also as an added reinforcement bar since compatibility of deformations is established. Its influence, however, is small due to its location at the centre of the cross section. The dimensions of the prestressing rebars and ducts are given in Table 1 . Columns are coded as $X X-Y Y$, where $X X$ is the bar diameter $(12 \mathrm{~mm}$ or $25 \mathrm{~mm})$ and YY is the squashing load ratio (30\% or $80 \%$ approx.) defined as $v=N /\left(0.85 \cdot f_{c t} \cdot b \cdot h\right)$, where $N$ is the axial load. The cross section of the columns is presented in Fig. 4.

\subsection{Material properties}

The concrete formulation is detailed in Table 2. It is a SelfCompacting Concrete (SCC) with a target strength of $f_{c k .28}=30$ MPa. The reason behind the use of SCC resides in the need to make sure that concrete penetrates correctly in the step above casting phase I at the bottom of the column, also due to reinforcement congestion in this zone. Table 3 shows the results of cylinder compression and indirect tension tests carried out at 7 and 28 days.

All longitudinal and transverse reinforcement provided is B-500S, with the properties shown in Table 4.

\subsection{Test instrumentation}

The following measurements were taken for each test:

- Applied displacement.

- Deflections at the load application point, and two intermediate sections $(z=\mathrm{L} / 3$ and $z=2 / 3 \mathrm{~L}$ ).

- Inclination at the load application point.

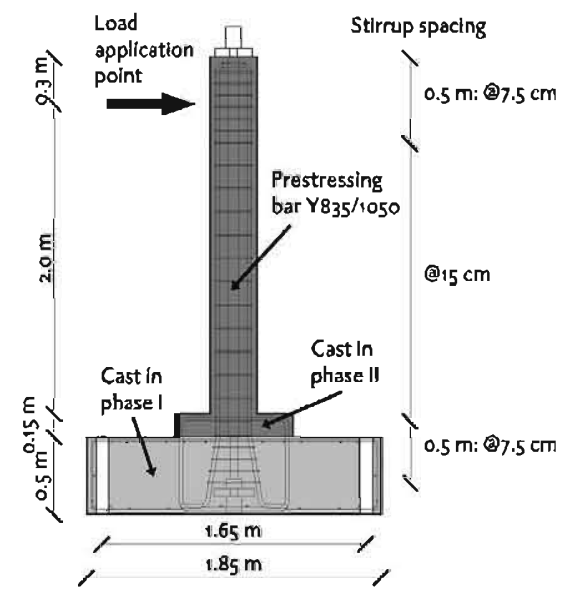

Fig. 3. Creometry of tested columins.

Table 1

Properties of prestressing system.

\begin{tabular}{llllll}
\hline $\begin{array}{l}\text { Squashing } \\
\text { load ratio } \\
(-)\end{array}$ & $\begin{array}{l}\text { Interior } \\
\text { duct } \emptyset \\
(\mathrm{mm})\end{array}$ & $\begin{array}{l}\text { Exterior } \\
\text { duct } \emptyset \\
(\mathrm{mm})\end{array}$ & $\begin{array}{l}\text { Rebar } \\
(\mathrm{mm})\end{array}$ & $\begin{array}{l}\text { Target initial } \\
\text { elongation } \\
(\mu \varepsilon)\end{array}$ & $\begin{array}{l}\text { Target } \\
\text { prestressing } \\
\text { force }(\mathrm{kN})\end{array}$ \\
\hline$\approx 30 \%$ & 51 & 57 & 32 & 2.81 & 450 \\
$\approx 80 \%$ & 63 & 69 & 47 & 3.46 & 1200 \\
\hline
\end{tabular}
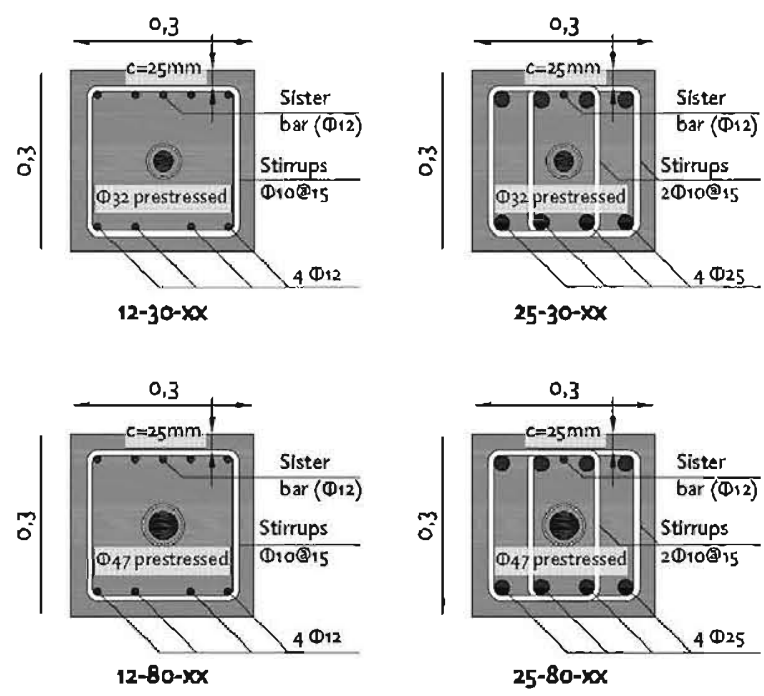

Fig. 4. Cross section of tested columns.

Table 2

Self-compacting concrete proportions per $\mathrm{m}^{3}$.

\begin{tabular}{ll}
\hline CEM ll AM(P-V) 42,5R & $400 \mathrm{~kg}$ \\
Water & $165 \mathrm{l}$ \\
$0 / 5 \mathrm{~mm}$ aggregates & $1004 \mathrm{~kg}$ \\
$5 / 10 \mathrm{~mm}$ aggregates & $821 \mathrm{~kg}$ \\
Superplasticizer & 3.71 \\
W/C & 0.41 \\
C/aggregates & 0.22 \\
\hline
\end{tabular}

Table 3

Mean cylinder compressive and indirect tension strength of concrete at 7 and 28 days.

\begin{tabular}{llll}
\hline $\begin{array}{l}\text { Mean cylinder compressive strength } \\
(\mathrm{MPa})\end{array}$ & $\begin{array}{l}\text { Mean indirect tensile strength } \\
\text { (MPa) }\end{array}$ \\
\hline 7 days $^{\prime}$ & 28 days $^{\text {h }}$ & 7 days $^{2}$ & 28 days $^{\text {b }}$ \\
32.3 & 37.5 & 3.3 & 4.2 \\
\hline
\end{tabular}

* 2 Specimens were tested at 7 days.

h 3 Specimens were tested at 28 days.

c Cylinder splitting test, often referred as "Brazilian" test

Table 4

Mechanical properties of reinforcing steel.

\begin{tabular}{ll}
\hline Characteristic yield strength $f_{y k}$ & $500 \mathrm{MPa}$ \\
Characteristic tensile strength $f_{\text {ck }}$ & $550 \mathrm{MPa}$ \\
Elastic modulus & $200,000 \mathrm{MPa}$ \\
Unit elongation at max. load & $12 \%$ \\
\hline
\end{tabular}

- Elongations of LDTVs placed at the column base. on the tensile and compressive faces, and at the reinforcement position on lateral faces, with a base of $50 \mathrm{~mm}$

- Strain along the compression zone, at both faces, in correspondence with the location of longitudinal reinforcement on the side of the column (compressive chord).

- Strain along the tension zone, at both faces, in correspondence with the location of longitudinal reinforcement on the side of the column (tensile chord).

- Strain along the tension face in correspondence with the location of longitudinal reinforcement. 


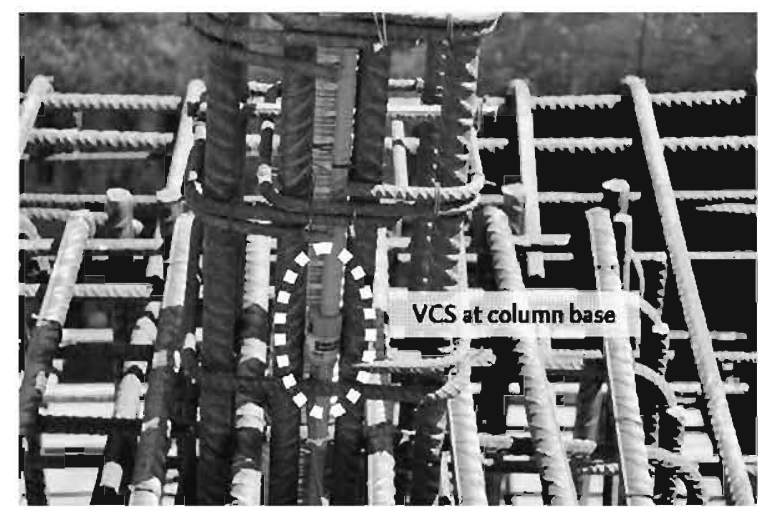

Fig. 5. Embedded vibrating chord sensor (sister bar) before casting:

All strain measurements (obtained along the full length of the column) were taken with digital extensometers with a base of $200 \mathrm{~mm}$.

Since a crack was expected to form at the column base (maximum bending moment), a Vibrating Chord Sensor (VCS), vertically centred in the column base and anchored at both ends with a $\emptyset 12$ rebar (sister bar), was embedded in the concrete as shown in Fig. 5. The advantage of this type of measurement, compared with a more traditional strain gauge, is that the mean value of the strain along the length of the sensor is given, while a strain gauge provides a local strain. The test was carried out using displacement control of the hydraulic jack with maximum displacement of $100 \mathrm{~mm}$ and maximum load of $200 \mathrm{kN}$.

The final instrumentation set-up is shown in Fig. 6.

\section{Results}

\subsection{Sectional stiffness}

The mean curvature of each segment (the term segment is used here to refer to the measurements basis. See for example definition of "segment no. 4 in Fig. 6) is evaluated according to Eq. (1):

$\chi_{\mathrm{i}}=\frac{\varepsilon_{\text {ten }, i}-\varepsilon_{\text {com }, i}}{d-d^{2}}$

where $\chi_{i}=$ curvature in the $i$-th segment; $\varepsilon_{\text {ten, } i}=$ strain in the tensile chord of the $i$-th segment; $\varepsilon_{c o m, i}=$ strain in the compressive chord of the $i$-th segment; $d-d^{\prime}=$ distance between chords, equal to $210 \mathrm{~mm}$.
The mean curvature in each segment is plotted against the applied moment at the centre of the segment for different load stages (the moment is calculated as the force in the jack times the distance between the jack application line and the centre of the segment), as shown in Fig. 7a-d. The moment-curvature graphs shown in this figure exhibit some scatter due to the fact that the strain measured in each segment is dependent upon the cracking pattern. Even so, the different measurements show a reasonably similar behaviour.

\subsection{Tension in rebars}

Steel elongation (and, therefore, in service, steel tension) is obtained from the readings of the VCS. By subtracting, to the elongation obtained at prestressing, the value before the test, the prestressing loss (due to thermal elongation, shrinkage and creep) can be obtained. This value is subtracted to the elongation after prestressing, to obtain the prestressing value at the test. These values are summarised in Table 5.

The tension in the rebars is plotted against applied bending moment in Fig. 8. The cracking moment for each column can be easily identified, and, as expected, is higher in specimens prestressed up to $80 \%$ of the squashing load. After cracking, there is a change of slope with stresses growing at a higher pace with respect to the increase of the bending moment. The change in the slope is greater for lightly reinforced columns (12-xx).

\subsection{Structural stiffress}

The structural response, understood in terms of imposed displacement measured in the head LVDT and measured force in the horizontal jack, is shown in Fig. 9.

Initial (uncracked) stiffness is similar for all four columns. When cracking occurs, the stiffness drop is smaller for heavily reinforced columns. Nevertheless, in this case the difference between cracked and uncracked phases for $12-\mathrm{xx}$ and $25-\mathrm{xx}$ series is remarkable.

Regarding ULS, it can be noted that column $12-80$ shows little ductility, having failed after spalling of concrete cover by buckling of $\emptyset 12$ rebars in compression. This is due to the fact that the stirrup spacing of $15 \mathrm{~cm}$ proved insufficient to avoid buckling of the longitudinal reinforcement in this case. By contrast, column 25-80, which showed the largest ductility, also experienced concrete spalling, but without rebar buckling. This fact points to the wellknown and well documented importance of confining concrete

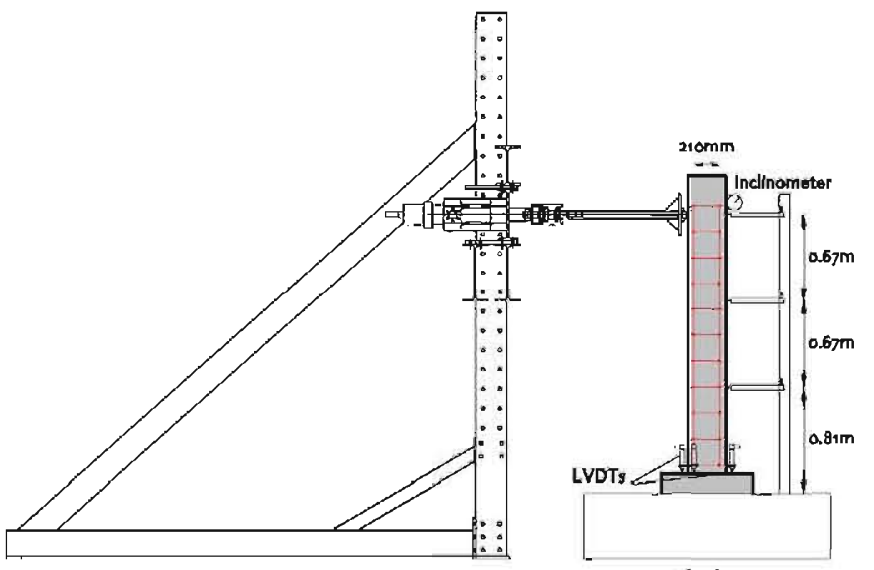

(a)

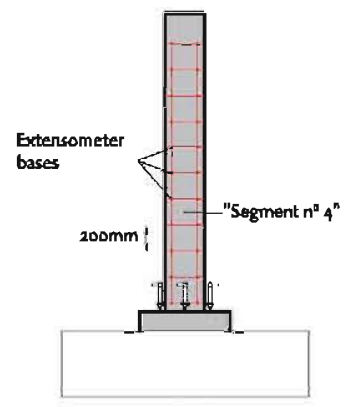

(b)

Fig. 6. Instrumentation of the test: (a) side and (b) front view 


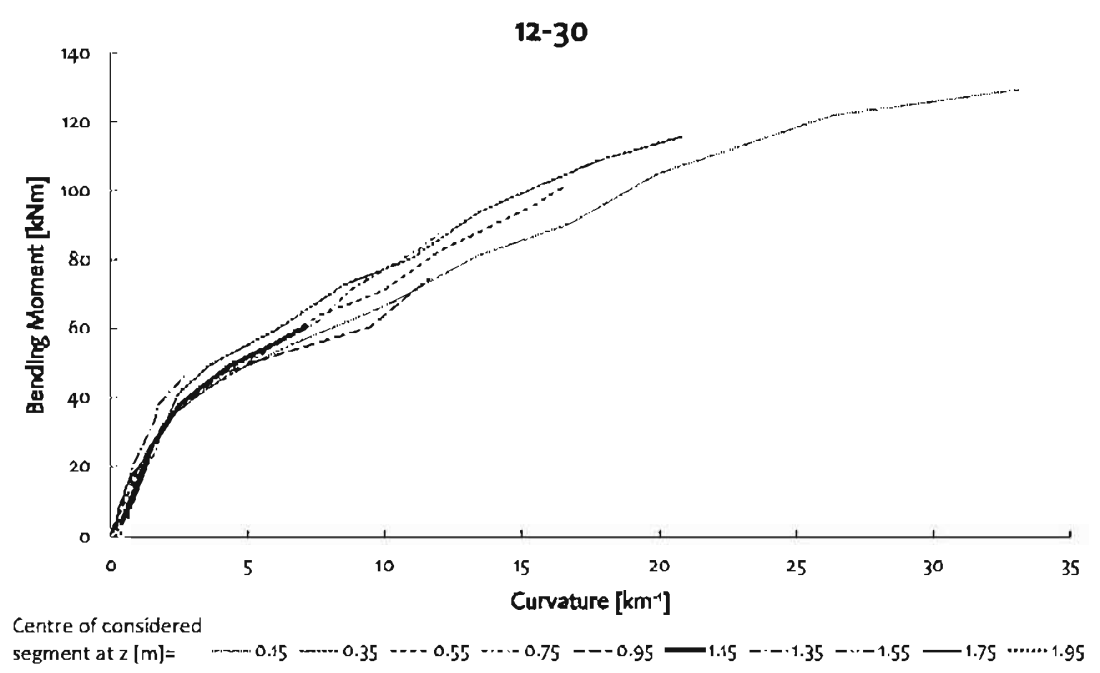

(a)

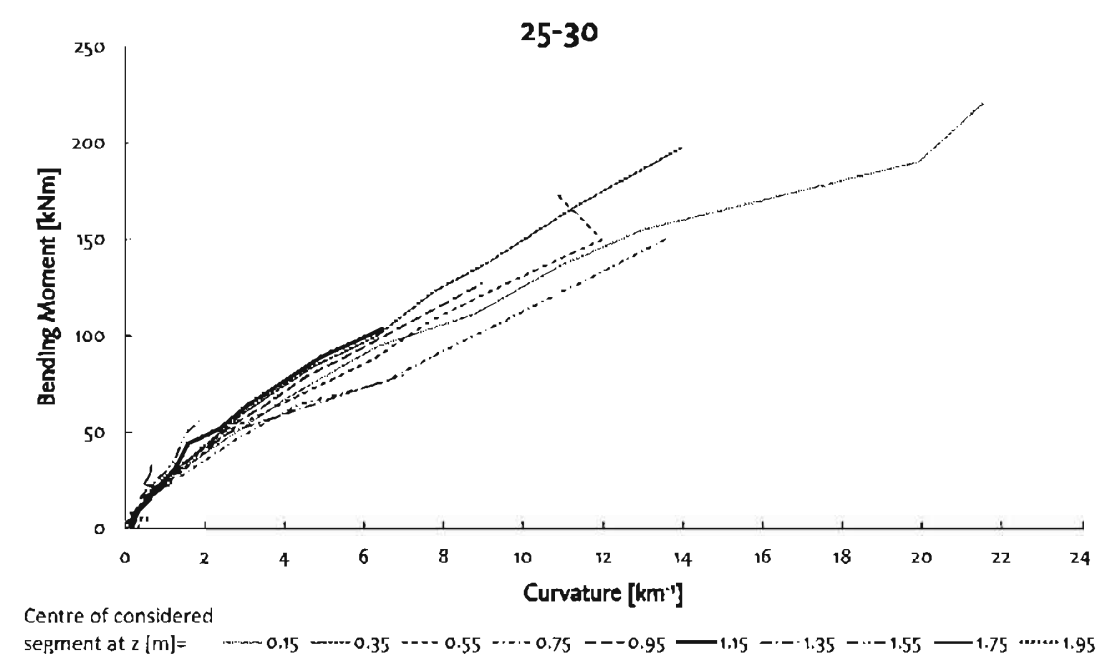

(b)

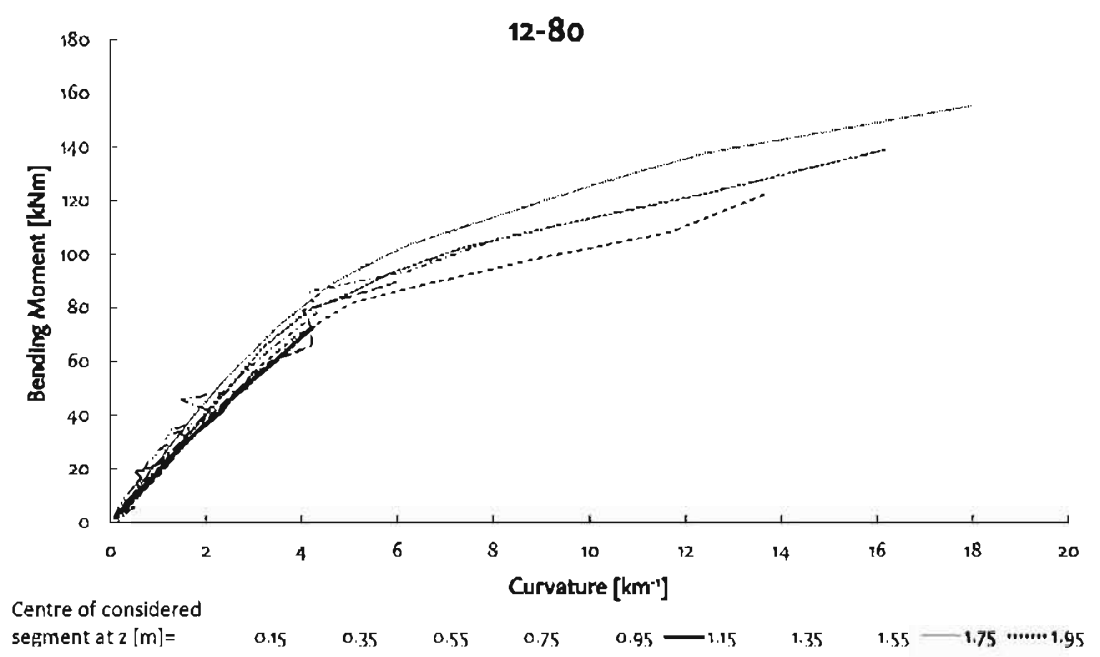

(c)

Fig. 7. Moment/curvature diagrams: $12-30$ (a), 25-30 (b), 12-80 (c) and 25-80 (d).

and longitudinal rebars, especially for low diameter rebars, when large displacements are expected in ULS.
Due to the test set-up (since the axial load was simulated using prestressing), no P-Delta effect takes place when the column is 


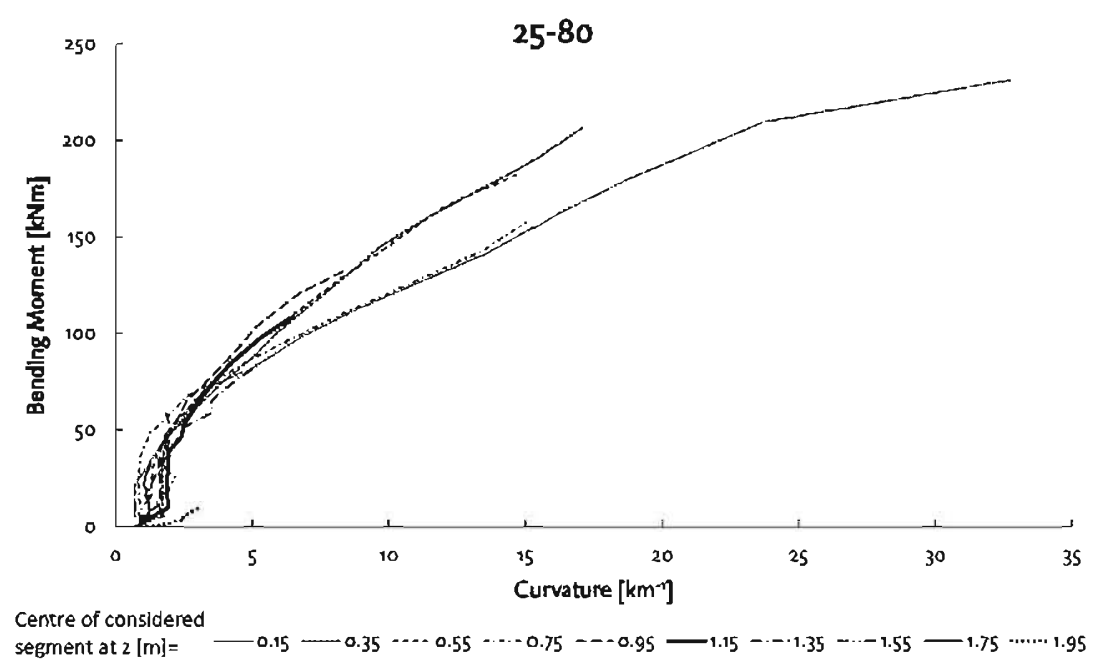

(d)

Fig. 7 (continued)

Table 5

Estimaled concrete strength and prestressing elongation at testing.

\begin{tabular}{|c|c|c|c|c|c|c|}
\hline Column & Date of test & $\begin{array}{l}\text { Age at testing } \\
\text { (days) }\end{array}$ & $\begin{array}{l}\text { Estimated strength } \\
\text { at testing (MPa) }\end{array}$ & $\begin{array}{l}\text { Prestressing } \\
\text { elongation }(\mu \varepsilon)\end{array}$ & $\begin{array}{l}\text { Estimated prestressing } \\
\text { force } N(\mathrm{kN})\end{array}$ & $\begin{array}{l}\text { Squashing load ratio } \\
\mathrm{N} /\left(0.85 \cdot \mathrm{b} \cdot \mathrm{h} \cdot f_{c d}\right)\end{array}$ \\
\hline $12-30$ & $27 / 09 / 2012$ & 113 & 41 & 140 & 440 & $29 \%$ \\
\hline $25-30$ & $25 / 09 / 2012$ & 111 & 41 & 130 & 500 & $33 \%$ \\
\hline $12-80$ & $02 / 10 / 2012$ & 118 & 42 & 348 & 1083 & $71 \%$ \\
\hline $25-80$ & $11 / 10 / 2012$ & 127 & 42 & 302 & 1151 & $75 \%$ \\
\hline
\end{tabular}

a According to ECZ \#3.1.2 and tests at 7 and 28 days. All columns were cast on 04/06/2012 and prestressed on $11 / 09 / 2012$.

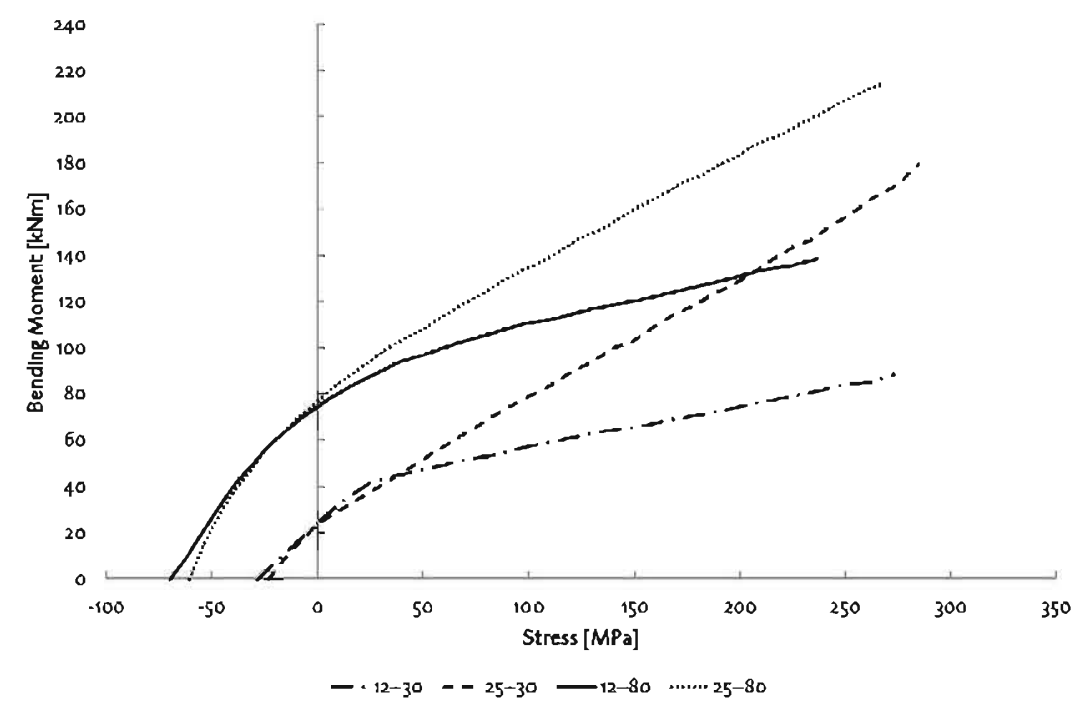

Fig. 8. Tension in rebars measured with VSC against applied bending moment.

laterally deformed. Nevertheless, second order effects for serviceability conditions ( $250 \mathrm{MPa}$ ) have been determined for each tested element assuming that the axial force was caused by external loading and not prestressing, as shown in Table 6.

It has been found that these effects are about $7 \%$, in terms of increase of bending, for an axial load of $30 \%$ of the column capacity and around $16 \%$ for a load of $80 \%$ of the column capacity. Second order effects are neglected in practice when they account for less than $10 \%$ of the bending moment. In practice quasi-permanent loads -which are of interest when assessing cracking of columnscan cause the axial load to be, at most $50 \%$ of the column capacity for buildings, and much less for bridges. ${ }^{2}$ For this load level it is expected that second order effects would increase bending moments in around $10 \%$ and can therefore be neglected for practical purposes.

\footnotetext{
2 The $80 \%$ load level was designed to cover the full spectrum, even though such levels of axial load can only be reached with factored load combinations.
} 


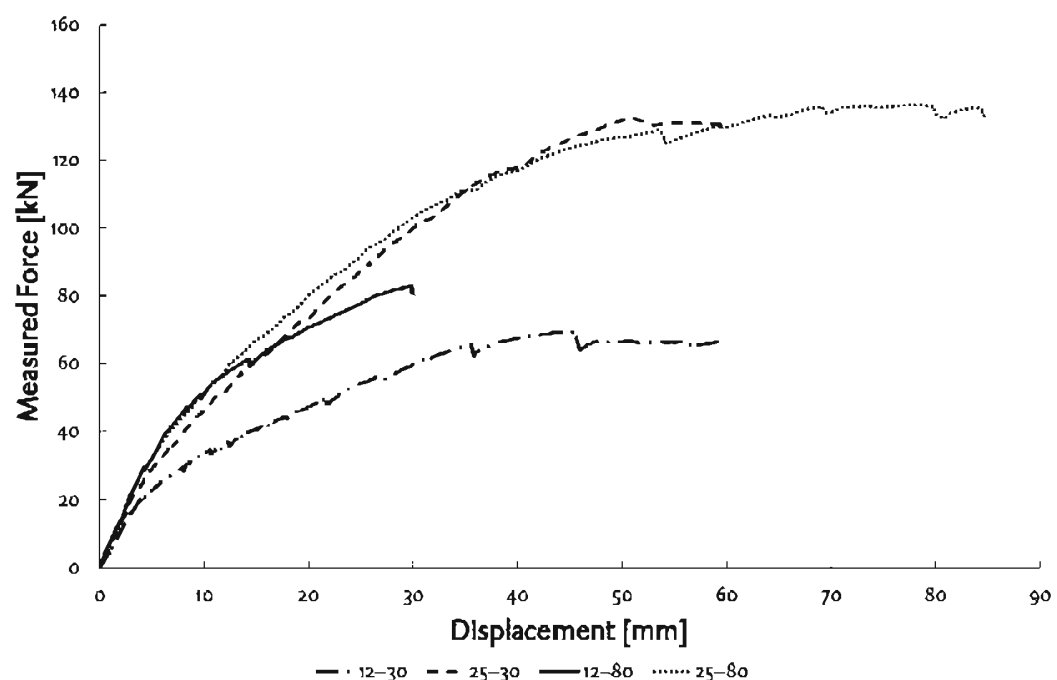

(a)

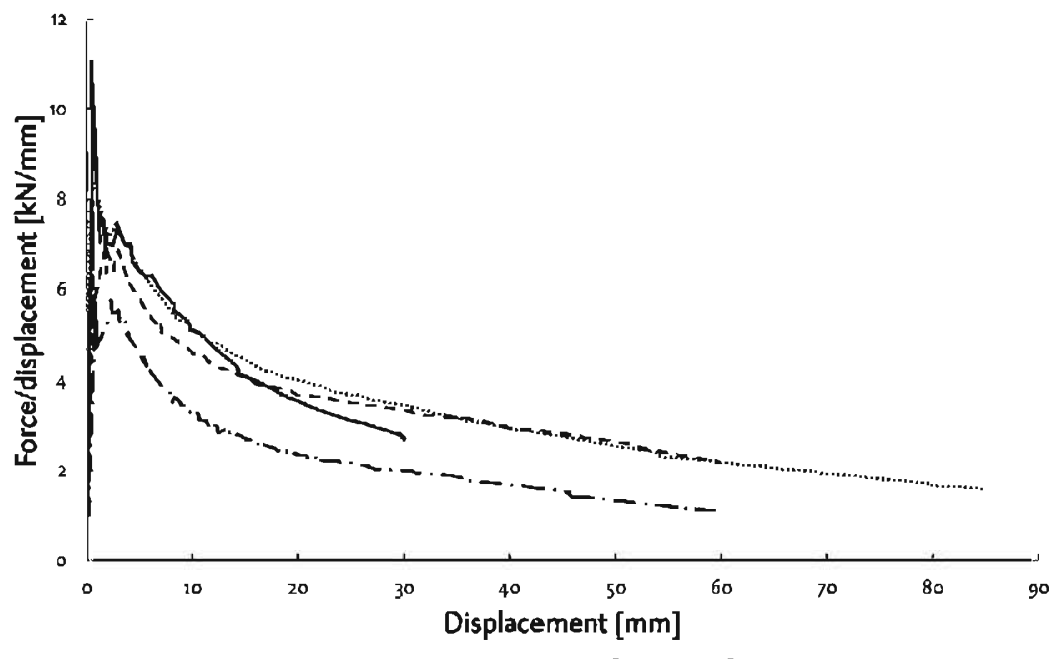

(b)

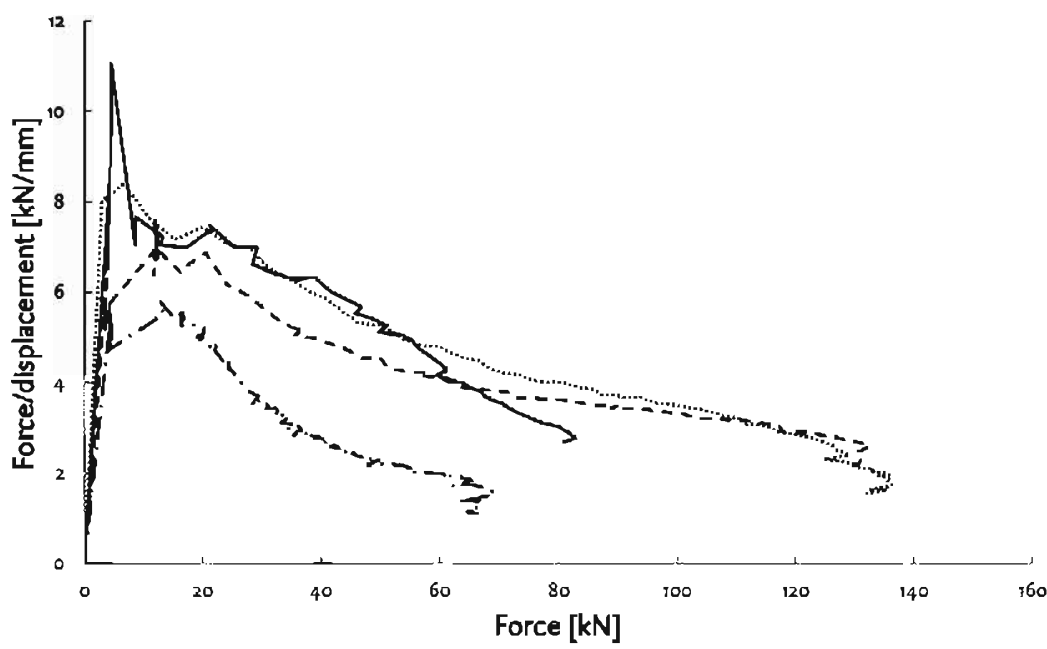

$-\cdot 12-30--25-30-12-80 \cdots \cdots \cdot 25-80$

(c)

Fig. 9. Force measured in the jack vs. imposed displacement (a); structural stifrness as force/displacement against displacement (b) or force (c). 
Table 6

Relevance of second order effects.

\begin{tabular}{cccccc}
\hline Column & $\begin{array}{l}\text { Axial } \\
\text { force } \mathrm{N} \\
(\mathrm{kN})\end{array}$ & $\begin{array}{l}\text { Serviccability } \\
\delta^{3}(\mathrm{~mm})\end{array}$ & $\begin{array}{l}\text { First order } \\
\text { moment } \\
\mathrm{M}^{\prime}(\mathrm{kN} \mathrm{nl})\end{array}$ & $\begin{array}{l}\text { Second order } \\
\text { monent } \\
\mathrm{M}^{\mathrm{N}}=\mathrm{N} \cdot \delta \\
(\mathrm{kN} \mathrm{m})\end{array}$ & $\begin{array}{l}\mathrm{M}^{11} / \mathrm{M}^{1} \\
(-)\end{array}$ \\
\hline $12-30$ & 440 & 13 & 85 & 6 & $7 \%$ \\
$25-30$ & 500 & 20 & 156 & 10 & $6 \%$ \\
$12-80$ & 1083 & 19 & 141 & 21 & $15 \%$ \\
$25-80$ & 1151 & 29 & 210 & 33 & $16 \%$ \\
\hline
\end{tabular}

a The displacement causing a $250 \mathrm{MPa}$ stecl stress is considered serviceability displacement

\subsection{Cracking behaviour}

The crack patterns at the end of the test for each column can be observed in Fig. 10a-d. In all cases, the first crack formed at the column embedment and is not represented. Maximum and minimum crack spacings are summarised in Table 7.

Crack spacing is influenced by the stirrups. In fact, the maximum crack spacing always occurred in zones of the columns where the cracking could be regarded as not yet stabilised, with values close to the stirrup spacing $(=15 \mathrm{~cm})$. Nevertheless, the crack spacing close to the base of the columns, where the cracking can be regarded as stabilised, was generally reduced by the formation of one or two cracks in between stirrups (except 12-30). This is in accordance with what is observed in [12]. Although stirrups can initiate a crack, sometimes cracks do not develop at stirrup locations, and they develop in between stirrups, so that bond mechanisms cannot be neglected when predicting crack spacing for crack width calculations, especially for estimating maximum crack width.

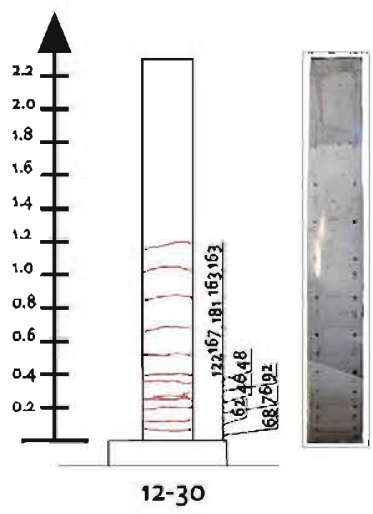

(a)

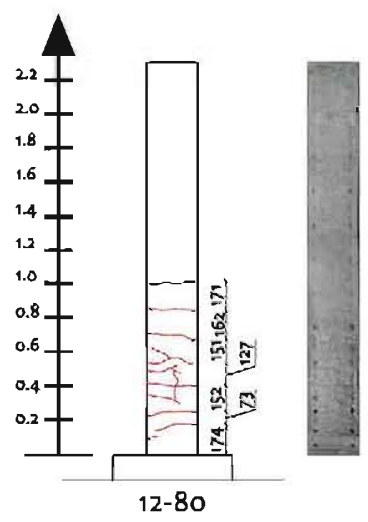

(c)

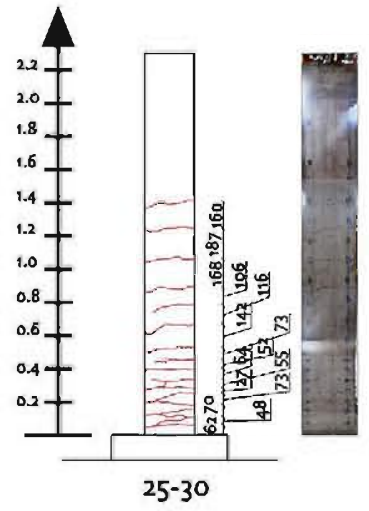

(b)

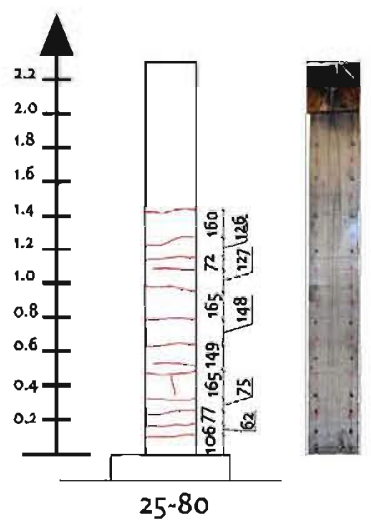

(d)
Fig. 10. Crack patterns at the end of the test
Table 7

Mean and maximum crack spacing at the cnd of the test.

\begin{tabular}{llll}
\hline & $s_{r, m}(\mathrm{~mm})$ & $s_{r, \max }(\mathrm{mm})$ & $s_{r, m} / s_{r, \max }(-)$ \\
\hline $12-30$ & 108 & 181 & 1.68 \\
$25-30$ & 90 & 187 & 2.08 \\
$12-80$ & 144 & 174 & 1.21 \\
$2.5-80$ & 118 & 174 & 1.47 \\
\hline
\end{tabular}

As already discussed in [12], measuring crack width by optical means is difficult and prone to errors. For this reason, in this study crack width is measured in two ways:

1. By considering the displacements of the LVDTs at the column base (frontal LVDT and mean value of the two lateral LVDTs). When the crack opens at the base, all the displacement of the LVDT is assumed to be due to the crack.

2. By multiplying the mean strain along the tensile chord in correspondence with the reinforcement both on the front of the column and on the side in each segment by the segment length $(=20 \mathrm{~cm})$ and dividing this number by the number of cracks. As discussed in [12], this method provides a reasonably good estimate of the value of the crack width, and is more reliable than direct crack measurements by traditional optical means.

Crack width measurements are presented in Fig. 11a-d against theoretical stress in the rebar assuming fully cracked section properties. It is worthy of notice that although maximum strain in rebars is expected at the column base, the maximum crack width does not always occur at that location since it is dependent on crack spacing. Therefore, the measurements given by LVTDs at the column base do not necessarily represent the maximum value of crack width.

For the same levels of tensile stress in rebars, cracks are smaller for $\emptyset 12$ columns $\left(\emptyset / \rho_{\text {s.e } \delta}=816 \mathrm{~mm}\right)$ than for $\emptyset 25$ columns $\left(\varnothing / \rho_{s, \text { eff }}=454 \mathrm{~mm}\right)$, which is contrary to the expected influence of the $\oslash / \rho_{5, e f f}$ parameter on cracking as pointed out in [12] (the larger $\emptyset / \rho_{\text {s.eff. }}$, the larger crack spacing and therefore crack width). The explanation for this resides in the fact that a first crack always developed at the column embedment, and the second one at the first stirrup position. Then, as the load increased, a third crack developed between the first two, but the "tension transfer efficiency" (that is, the effect governed by $\theta / \rho_{s, \text { enj }}$ ) of both reinforcement arrangements prevented the formation of new ones. Therefore, in this case, crack width was controlled by crack spacing, which was not controlled only by transfer length, and therefore $\emptyset / \rho_{s, e f f}$ effect turned out to be not visible at the bottom of the column. On the other hand, it can be noted that the limit of $w=0.3 \mathrm{~mm}$ (which is usual in engineering practice) is reached for values of theoretical steel stress $200-300 \mathrm{MPa}$, supporting the idea of applying a stress criterion within this range to design new structures as a way of controlling crack width to admissible values.

\section{Experimental verification of the simplified method}

The assumptions of the method have already been discussed in paragraph 2 . In particular, it has already been pointed out that the method proposed in [1] does not take into account TS effects.

Nevertheless, when comparing experimental results with the prediction of the method, it is interesting to study TS effects which are necessarily measured in an experimental campaign. In order to study the effect of TS also from a theoretical point of view, a second analysis has been performed, this time using the non-linear steel properties represented in Fig. 12. TS has been modelled according 


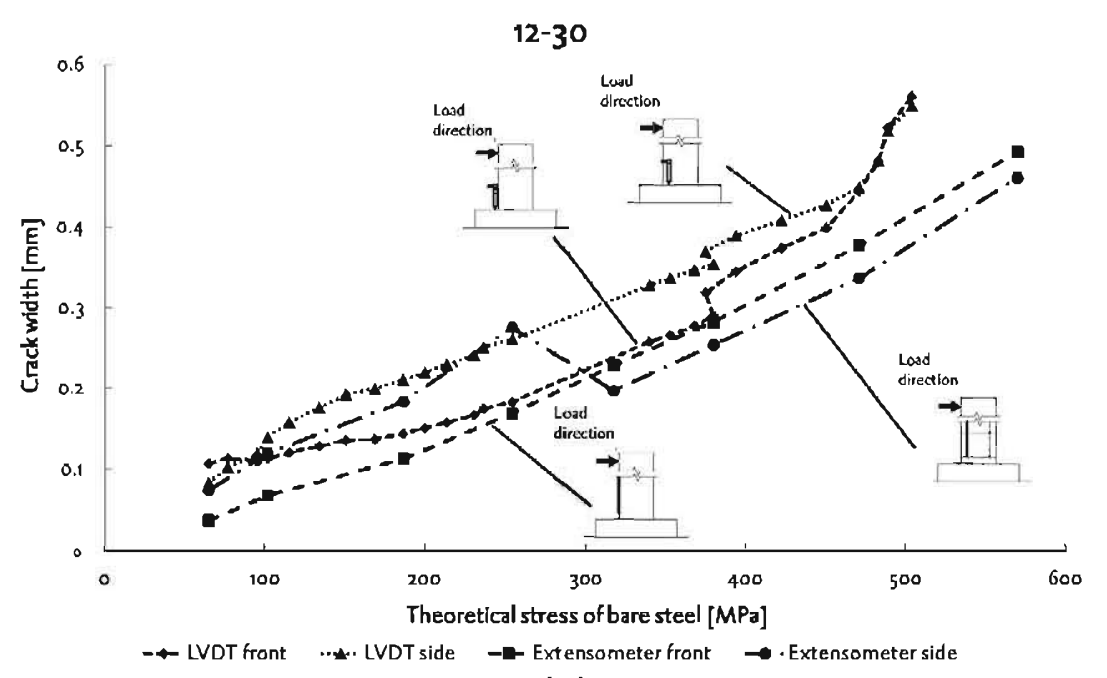

(a)

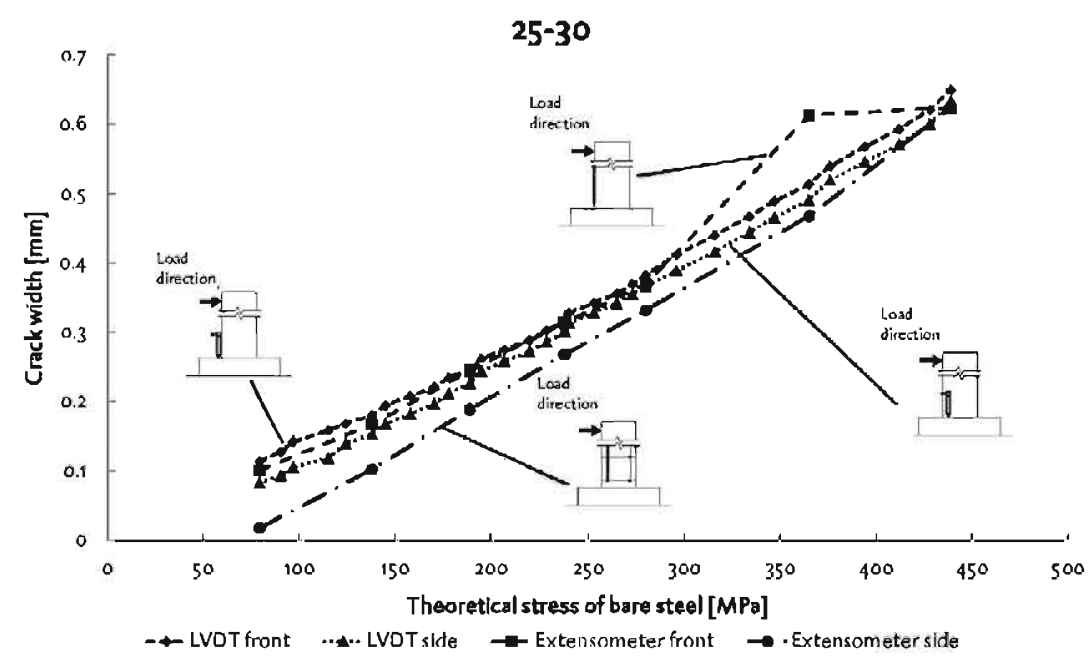

(b)

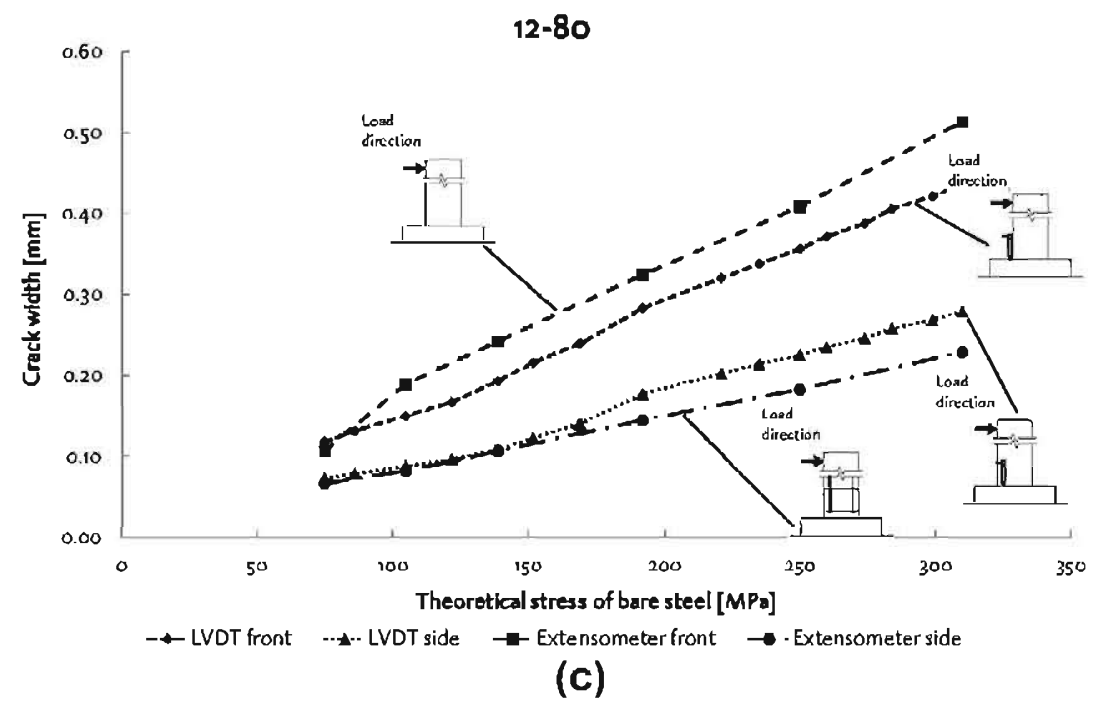

Fig. 11. Crack widtls measurements: $12-30$ (a), 25-30 (b), 12-80 (c) and 25-80 (d).

to MC2010 [13], with a slight procedural modification, considering concrete as a linear material in compression and also in tension up to the assumed value of the tensile strength.
The results of this non-linear analysis are presented in Fig. 13, along with the simplified method of [1] and the experimental results. As can be observed, the effect of TS is important only for 


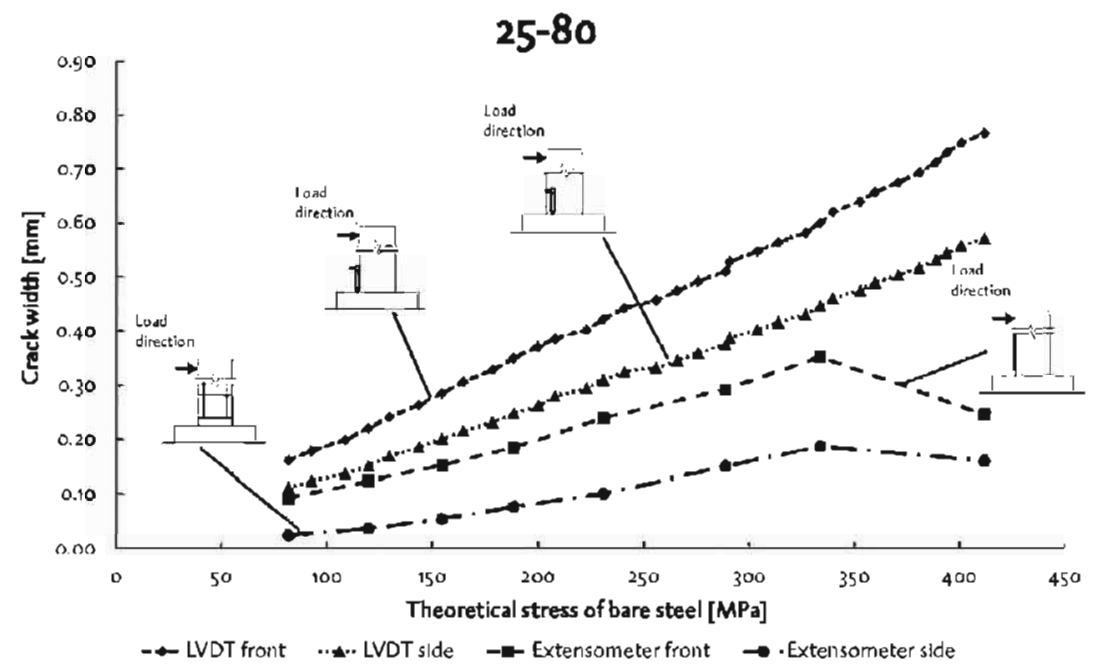

(d)

Fig. 11 (continued)

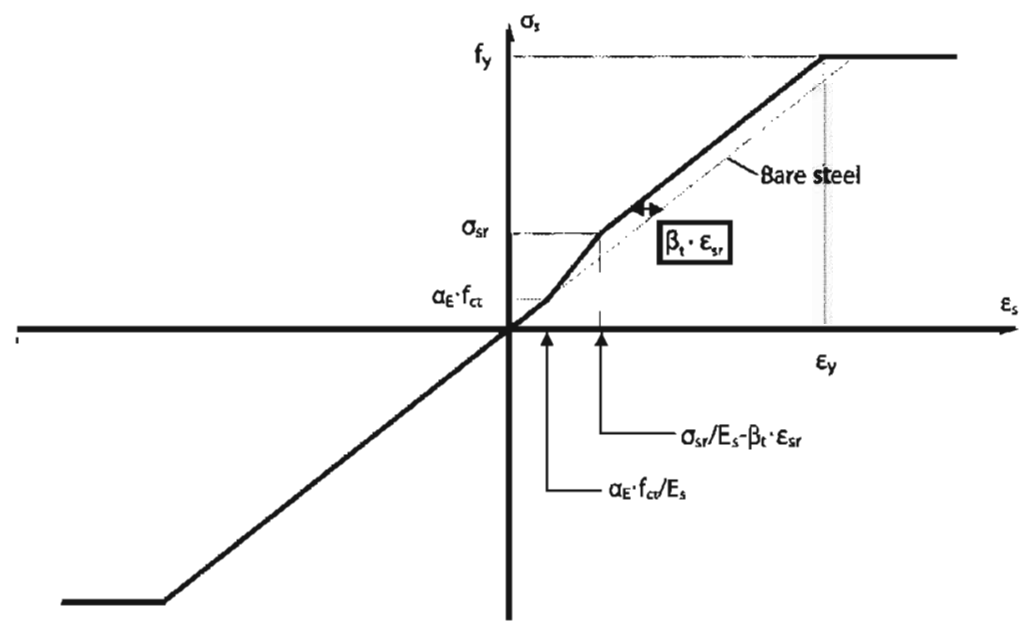

(a)

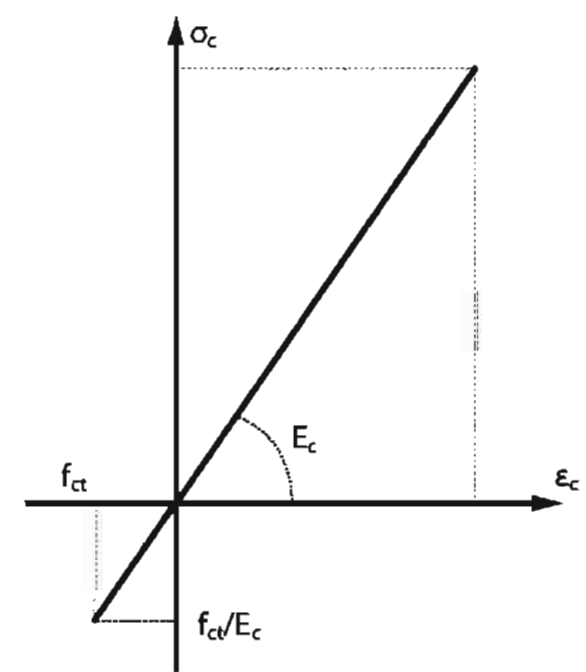

(b)

Fig. 12. Constitutive law of steel (a) and concrete (b) for non--linear sectional analysis $B=0.6$. 
column 12-30. given its low reinforcement and squashing load ratios. For the other columns, TS effects are negligible. Also Fig. 13 shows good agreement between experimental results and the simplified method of analysis [1], the analytical results, obtained with the above hypothesis, being a good and conservative approximation to the experimental results.

\section{Application to typical structures}

Using the method of Ref. [1], based on charts to simplify the design process, it is possible to consider both instantaneous and time-dependent imposed deformations, and their interaction. This

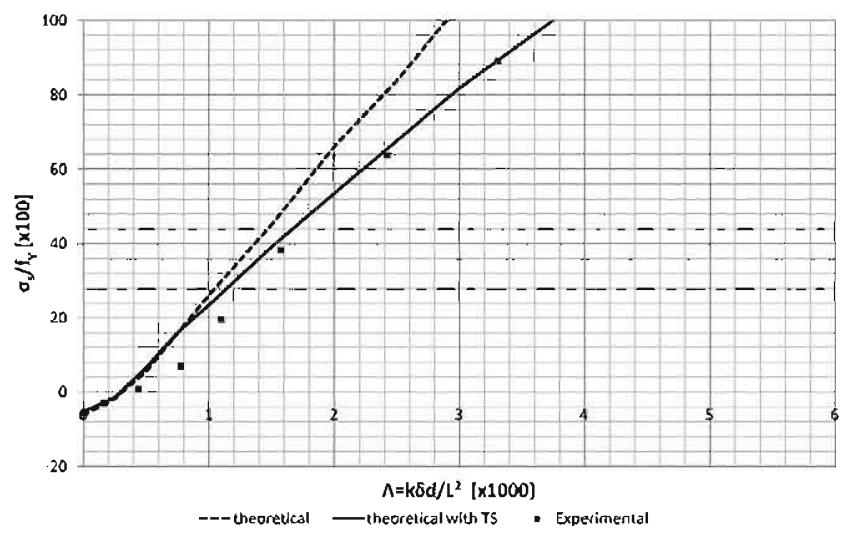

(a)

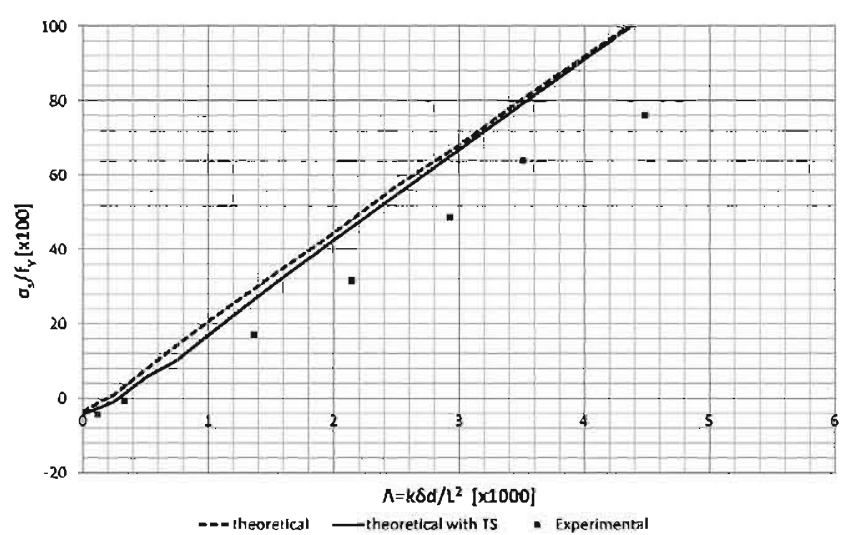

(b)

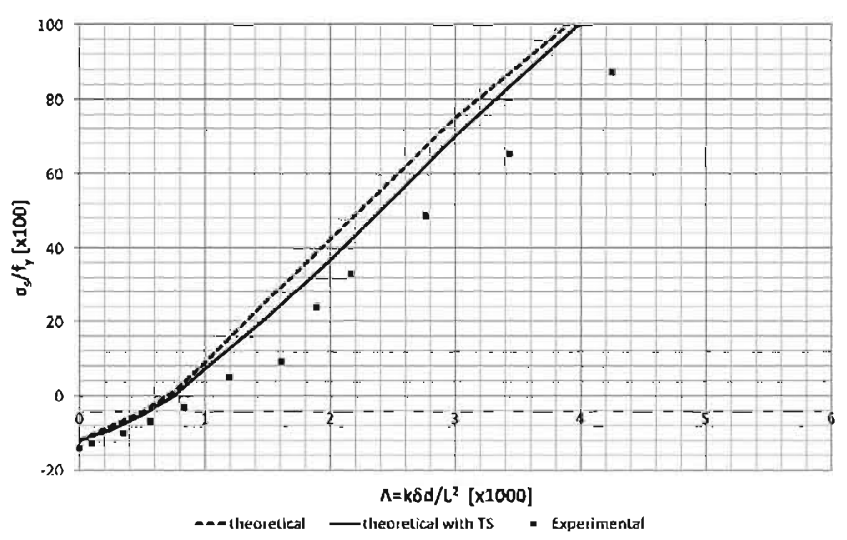

(c)

Fig. 13. Experimental verification of the simplified method: $12-30$ (a), 25-30 (b), $12-80$ (c) and 25-80 (d).

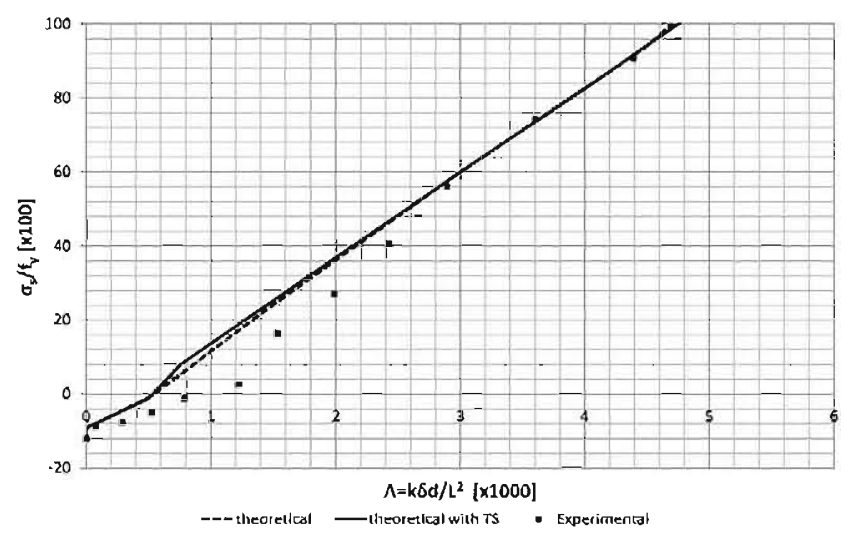

(d)

Fig. 13 (continued)

tool can be applied to obtain an estimate of the maximum jointless length which can be achieved with reasonable steel quantities and good serviceability conditions for typical structural applications such as standard buildings or overpasses.

In this paragrapl, graphs obtained using the simplified method, and representing the maximum jointless length of the structure as a function of the reinforcement ratio $\left(\rho_{s}=A_{s} / b h\right)$ of the support located farthest from the fixed point are presented. The curves have been generated for typical squashing load ratios $v=N /\left(0.85 b d f_{c u}\right)$ and target values of the admissible stress in the reinforcement $\left(\sigma_{s}\right)$.

In order to obtain these design aids, ordinary magnitudes of the involved parameters ${ }^{3}$ have been considered. A first graph, drafted for instantaneous imposed displacements $\left(\Lambda_{0}\right)$, is used to determine the value of $\sigma_{s}$ due to temperature effects $\left(\sigma_{s, 0}\right)$. Then, this value is used in a second graph together with a typical value of $\Delta \Lambda_{\infty}$ to obtain the total stress in reinforcement due to imposed displacements, following the procedure outlined in paragraph 2.

\subsection{Highway overpass}

Integral bridges are gradually becoming an attractive design option for projects with relatively moderate spans. For this application example a prestressed hollow-core girder bridge has been chosen. Piers are clamped at both ends. Their height is $7.0 \mathrm{~m}$ and the cross section is rectangular, $1.0 \mathrm{~m}$ thick, as shown in Fig. 14.

Two possible amounts of total imposed strains have been applied, 600 or $900 \mu \varepsilon$. They represent a mild or severe temperature variation coupled with a moderate or higher shrinkage strain. The proportion between long-term deformations and instantaneous deformations is equal to 1.0 in the first case and equal to 1.25 in the second one. ${ }^{4}$ The creep coefficient is taken as 2 .

As can be observed the higher the squashing ratio (the figure shows values of 0.5 and 0.3 for the squashing ratio), the longer is the jointless length which can be obtained. An increase of the reinforcement ratio generally implies an increase of the maximum length ( $L_{\max }$ ). The relationship between $L_{\max }$ and $\rho$ is, however, non-linear and increasing $L_{\text {mux }}$ becomes relatively more expensive as $\rho$ becomes larger. For an integral bridge of these approximate dimensions $L_{\text {max }}$ ranges approximately from 35 to $70 \mathrm{~m}$. assuming a maximum stress in steel of $250 \mathrm{MPa}$ for the quasi-permanent load combination, or $40-80 \mathrm{~m}$ with an allowable stress of $300 \mathrm{MPa}$. These values, which are relatively modest may be

\footnotetext{
${ }^{3}$ The involved parameters are the normalised displacement $A=k \delta d / L^{2}$, the elfective depth $d$ and the height of the column $h$.

${ }^{4}$ Low imposed strain: $\varepsilon_{\mathrm{T}}=300 \mu \varepsilon: \varepsilon_{\mathrm{x} / \mathrm{h}}=300 \mu \varepsilon$. High imposed strain: $\varepsilon_{\mathrm{y}}=400 \mu \varepsilon_{\mathrm{i}}$ $\varepsilon_{\mathrm{N} / 2}=500 \mu \varepsilon$
} 

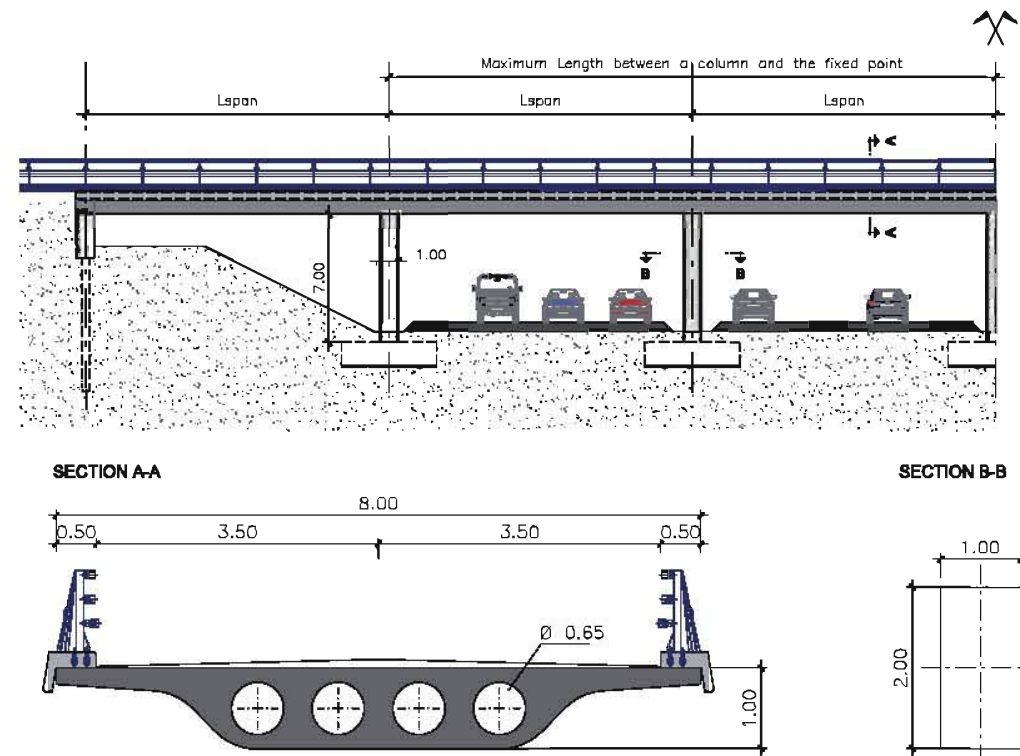

SECTION B-B

Fig. 14. Typical longitudinal prospect of a highway overpass.

improved by reducing the width of the piers or increasing their height, and points to the need of modifying typical design criteria if longer jointless spans are to be achieved (see Fig. 15).

The instantaneous imposed deformation used in this calculation corresponds to a uniform temperature variation of $20^{\circ}$ or $40^{\circ}$, reduced by the $\psi_{2}$ combination coefficient for quasi-permanent values, taken as 0.5 (according to Eurocode [14]). In addition to the temperature load, $200 \mu \varepsilon$ are considered to be present due to the instantaneous deformation of the deck as a result of the application of the prestressing force. The long-term imposed deformation used in this calculation $\left(\varepsilon_{s h}\right)$ is supposed to be fully due to shrinkage. The shrinkage strain is therefore assumed to be 300 or $500 \mu \varepsilon$.

However, this can be regarded as a simplification since due to cracking in the columns their displacement due to creep is liable to be somewhat smaller than the displacement of the prestressed deck, thereby inducing some stresses in the reinforcement. It is assumed however that these stresses will normally be small. Moreover, considering the column embedded at both ends is conservative, since on one hand some rotational capacity of the foundation could be considered (depending, of course, on the type of foundation and soil), and, on the other, the deck has the same thickness as the pier, therefore its stiffness is not infinite compared to that of the pier. Therefore the above values of maximum lengths are deemed to be conservative.

\subsection{Long jointless building}

Similarly to the case of the integral bridge, in this section charts to estimate the maximum jointless length of a typical building are presented. For this purpose, the following data, usual in building design, has been considered:

- First floor height: $3.00 \mathrm{~m}$.

- Square columns, side dimension: $0.30 \mathrm{~m}$.

- Imposed deformation: $775 \mu \varepsilon$.

Imposed deformations are usually divided into instantaneous strains due to temperature and time dependent strains due to shrinkage and creep deformation, i.e. $\varepsilon=\varepsilon_{T}+\varepsilon_{s h}+\varphi \varepsilon_{c 0}$. Nevertheless, for building structures, thermal deformations are not considered by Eurocode [14] in the quasi-permanent combination

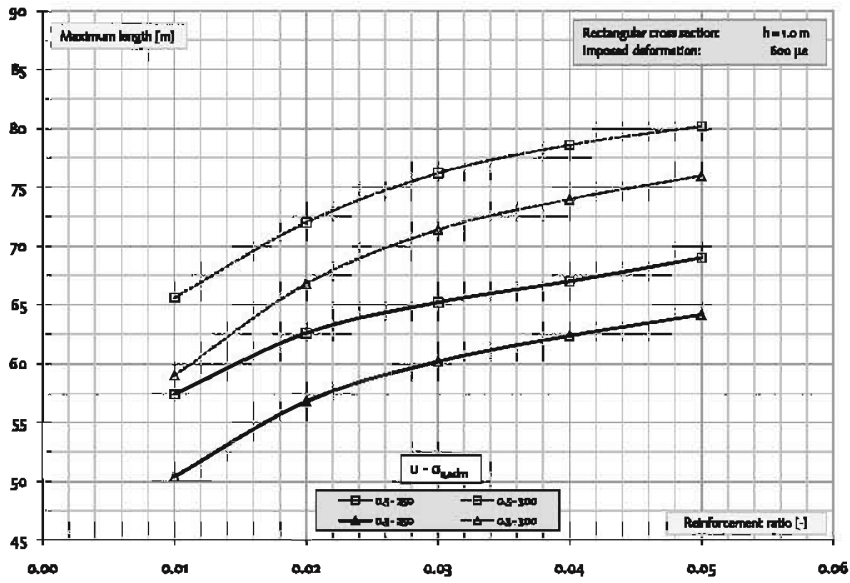

(a)

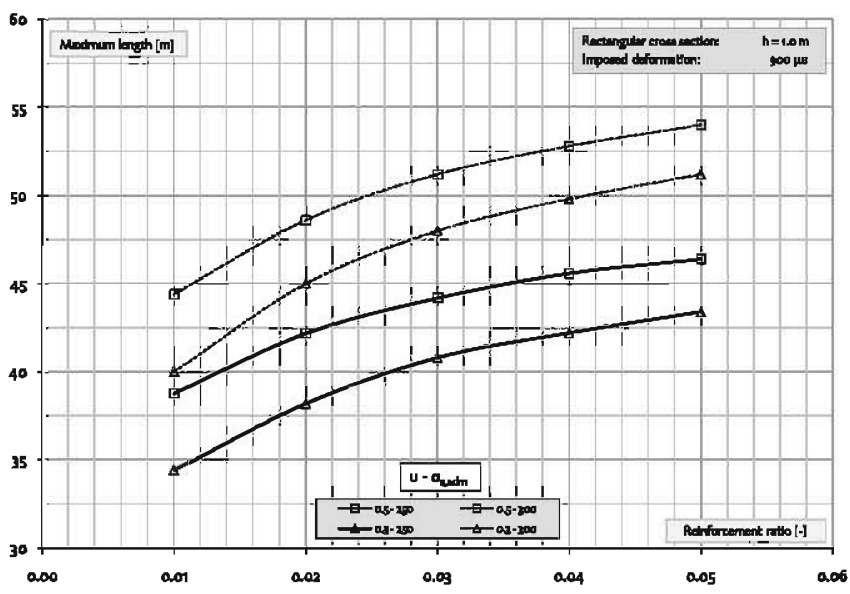

(b)

Fig. 15. Maximum length of the bridge (calculated as twice the maximum allowable distance between the fixed point and the farthest pier) as function of the reinforcement ratio: low imposed deformations (a) and high imposed deformations (b) 
defined in Eq. (2), where the corresponding combination coefficient $\psi_{2}$ is zero for temperature.

$\sum_{j \geqslant 1} G_{k, j}+P+\sum_{j \geqslant 1} \psi_{2, i} Q_{k, i}$

Due to cracking of concrete, the initial strain at the centre of the cross section $\varepsilon_{C 0, c g}$, will, regardless of the sign of the bending forces, be a tensile strain (see Fig. 16. Plane A) which would partially compensate the shortening due to rheological effects (see Fig. 16. Planes $\mathrm{B}$ and $\mathrm{C}$ ). This phenomenon is sometimes referred to in literature (see $[11,15]$ ) as beam growth. In the current analysis, this instantaneous effect has been neglected since it can only be considered in its full magnitude if cracking takes place after the full length of the structure has been built. If, as is normal in building practice, the structure is cast in several stages and the horizontal slab cracks after removing the formwork (which is reused in the next stage), the extension due to beam growth will not accumulate over the whole length of the structure, but over a much smaller length and this effect will be much smaller in terms of displacement at the top of the columns. Neglecting this effect provides conservative estimates of the maximum jointless length.

As shown in Fig. 16, in a simplified manner (see $[16,17]$ ), the variation of the deformation plane caused by shrinkage and creep, can be approximated as a rotation around the tensile steel fibre. Imposed deformations at the centre of the slab can then be approximately taken as $45 \%$ (see explanation of this figure below) of this total value. It is worth to point out that this last assumption does not apply to the case of prestressed elements (slabs in buildings or decks in bridges) since no cracking is usually envisaged.

The increase of strain due to creep may be estimated by assuming a worst case scenario in which at the critical cross-section (probably the support) the maximum quasi-permanent compressive strain (considering that stress state in concrete is within the linear creep region) in concrete is:

$\varepsilon_{c 0}=\frac{0.45 \times f_{c k}}{E_{c}} \cong \frac{0.45 \times 25}{30,000}=375 \mu \varepsilon$

The strain of the centre of gravity of the uncracked section can therefore be estimated as in [16]:

$\varepsilon_{c g}=\frac{\varphi \varepsilon_{c 0}+\varepsilon_{s h}}{1+12 \alpha \rho^{\prime}} \times \frac{h / 2}{d} \cong \frac{\varphi \varepsilon_{c 0}+\varepsilon_{s h}}{1+12 \alpha \rho^{\prime}} \times \frac{h / 2}{0.9 h}=\frac{\varphi \varepsilon_{c 0}+\varepsilon_{s h}}{1+12 \alpha \rho^{\prime}} \times \frac{1}{1.8}$

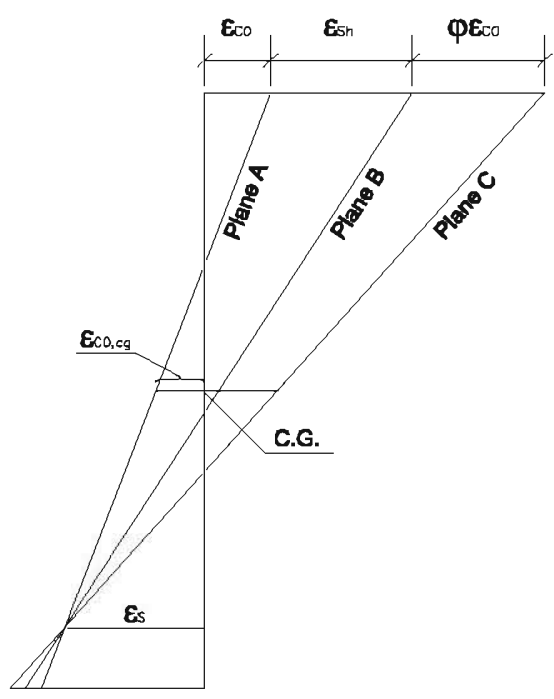

Fig. 16. Approximate increase of curvature due to creep and shrinkage (rotation around the reinforcement is assumed as a simplification [16]). where $\alpha$ is modular ratio and $\rho^{\prime}$ is compression reinforcement ratio. Considering values of $6.67 \%$ and $2.8 \%$ respectively for these variables, Eq. (4) becomes:

$\varepsilon_{c g}=\frac{\varphi \varepsilon_{c 0}+\varepsilon_{s h}}{2.2}$

For the example being studied the resulting values are as follows:

$\varphi=2.0$

$\varepsilon_{c o}=187.5 \mu \varepsilon$

$\varepsilon_{s h}=400 \mu \varepsilon$

$\varphi \varepsilon_{c o}+\varepsilon_{s h}=2 \times 187.5+400=775 \mu \varepsilon$

$\varepsilon_{\text {cg }}=\frac{775}{2.2} \cong 350 \mu \varepsilon$

Fig. 17 shows the maximum jointless length for different values of the reinforcement ratio, considering a total strain at the most compressed fibre equal $775 \mu \varepsilon$ due shrinkage and creep with a creep coefficient of 2.0 as detailed above. The chart presented in Fig. 17 is obtained considering a design value of $350 \mu \varepsilon$ corresponding to the strain of the centre of gravity of the slab.

Fig. 18 shows the same results for a generic value of the timedependent strain. The vertical axis represents in this case the product of the maximum jointless length times the imposed strain due to creep and shrinkage.

In the previous charts, the hypothetical length considering full development of the steel elastic branch (i.e. a tension of

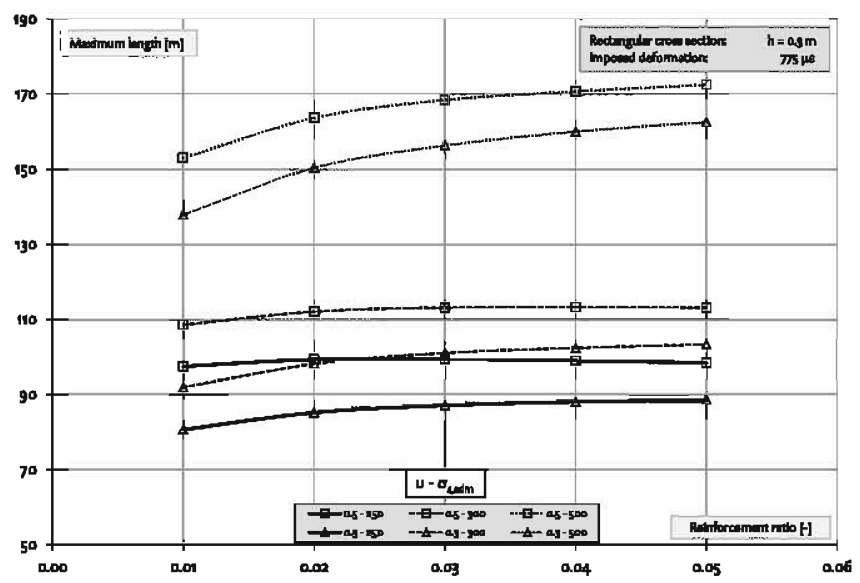

Fig. 17. Building with typical value of $\mu \varepsilon$ imposed deformation.

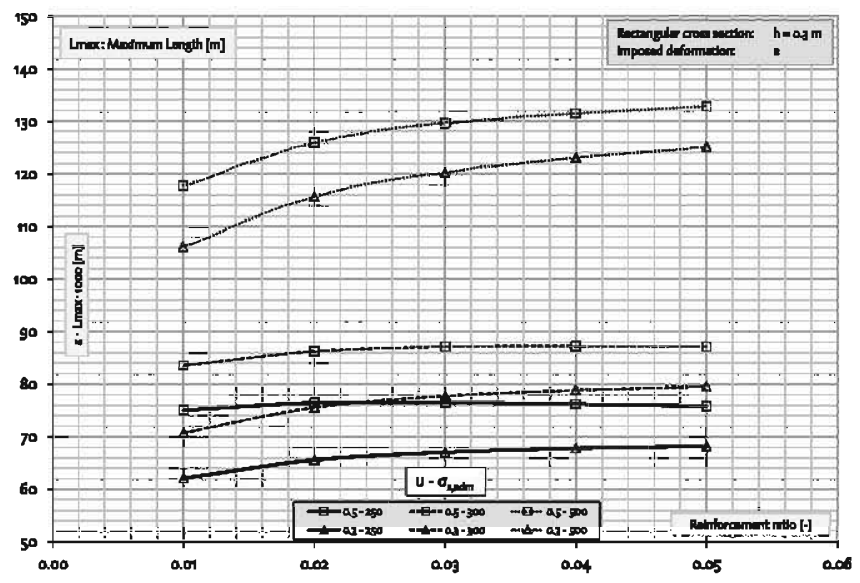

Fig. 18. Maximum jointless length for a generic time-dependent strain. 
$500 \mathrm{MPa}$ ) is also presented. This case is interesting because, besides representing the upper bound of the problem, it shows that if better crack control can be achieved, for instance by the addition of fibres, longer jointless buildings can be designed (as already noted and experimentally observed, the stress limitations to $250 \mathrm{MPa}$ or $300 \mathrm{MPa}$ are basically due to crack width control).

\subsection{Comparison with code rules}

As seen above, depending on the design criteria (maximum allowable stress), the type of structure and the considered value of imposed deformations, the maximum lengths which can be reached are of up to $80 \mathrm{~m}$ for a typical bridge and up to $170 \mathrm{~m}$ for a typical building structure.

In codes provisions for maximum jointless lengths are only found for buildings structures (for a good summary, see Ref. [18], chapter 2). Such limits are meant as inferior values which liberate designer from the analysis of structural effects of imposed deformations. As such however, these limits have, in practice, become generalized as design criteria. Examples of this type of clause can be found in:

EN 1992-1-1 [19] 2.3.3 (3) in which is stated that "In building structures, temperature and shrinkage effects may be omitted in global analysis provided joints are incorporated at every distance $d_{\text {joint }}$ to accommodate the resulting deformations". $d_{\text {joint }}$ Is a nationally determined parameter whose recommended value is $30 \mathrm{~m}$.

The Spanish building code CTE in part DB SE-AE [20] states that thermal actions on structures can be neglected if joints are placed every $40 \mathrm{~m}$.

The old French standard BAEL 91 [21], allows jointless length which vary between 25 and $50 \mathrm{~m}$ depending on the climatic conditions.

These limits seem to be on the low side. Fig. 18 shows that, in the worst case, for a typical building structure, lengths of over $60 \mathrm{~m}$ should not be a problem. It seems, therefore that current practice can be over-conservative.

\section{Conclusions}

From the discussion of the previous paragraphs, the following conclusions can be drawn:

- For the tested specimens, the simplified method for serviceability design of jointless structures provided safe and reasonably accurate predictions in terms of tensile stress of the rebars vs. imposed displacement.

- The original method, proposed by the authors, was modified by including tension-stiffening in serviceability analysis of jointless structures. It is shown that such a modification might be very effective for the analysis of structures with small amount of reinforcement subjected to axial loading of low intensity. It was experimentally proven that, for such elements, the tension-stiffening effect may lead to an increase in the length of jointless spans of up to $20 \%$. With increased reinforcement ratio or load intensity, the tension-stiffening effect becomes insignificant.

- The usual stress limitations of engineering practice (between 250 and $300 \mathrm{MPa}$ ) are a good reference to control crack width to acceptable values (up to $0.3 \mathrm{~mm}$ ). Therefore (providing proper confinement for ULS) it can be argued that if crack width is better controlled by other means than tensile reinforcement, such as addition of fibres, longer jointless spans can be achieved.

- The application of the simplified method to typical bridge and building structures provides a useful reference for designing long jointless structures. In particular, it has been proved that, depending on the type of the structure and the boundary conditions of the problem, longer jointless spans than those usual in engineering practice can be designed without serviceability problems. This is specially the case for buildings. In the case of bridges, designs need to be adjusted (smaller column depth and greater heights) in order to increase the jointless spans. This should also encourage engineers and clients to adopt jointless solutions.

\section{Acknowledgements}

The tests carried out at the Structures Laboratory of the Civil Engineering School of UPM were performed within the framework of the Research program Uso de hormigones con fibras metálicas de NFU en estructuras integrales lead by COMSA EMTE, S.A. and was partially funded by Centro de Desarrollo Tecnológico Industrial (CDTI) an organism of the Spanish Ministry of Science and Technology, under Project Number IDI-20110480.

The authors also wish to thank the Laboratory head José Torrico, Laboratory technicians Isidro García and Miguel Ángel Peña, and Freddy Ariñez Fernández for their invaluable help designing and carrying out the tests.

\section{References}

[1] Pêrez A, Corres H, Petschke T, Ezeberry J, Giraldo A. Serviceability design of columns of long jointless structures. Eng Struct 2012;44.

[2] Ministerio de Fomento. Guía para la concepción de puentes integrales en carreteras, Madrid; 2000.

[3] British Department of Transport. Design manual for roads and bridges, vol. 1, Section 3, Part 7-8: Desiggn for durability; 1995.

[4] Ndon U], Bergeson KL. ThermaI expansion of concretes: case study in Iowa. J Mater Civ Eng 1995;7(4).

[5] Petschke T, Corres H, García E, Pêrez A. Imposed deformations in concrete: case study of an underground car park. J Mater Civ Eng 2011;24(12).

[6] Camara J. Structural response and design criteria for imposed deformations superimposed to vertical load effects. In: Proceedings of the 2 nd FIB international congress, Naples; 2006.

[7] Najdanovic D. Contribution à la vêrification de l'êtat d'utilisation des colonnes sous dêformations imposêes. PhD Thesis, Institut de statique et structures en bêton armê et prêcontraint, Lausanne; 1987.

[8] Alavizadeh-Farhang A. Concrete structures subjected to combined mechanical and thermal loading. Dissertation, Royal Institute of Technology, Stockholm; 2000 .

[9] Gilbert RI. Shrinkage, cracking and deflection - the serviceability of concrete structures. Electr I Struct Eng 2001; 1; 1).

[10] Ezếueiríy J. Comportamiento tếinico de eslementos de hormigón estructural en condiciones de servicio, sometidos a cargas exteriores y deformaciones impuestas. Dissertation, Polytechnic University of Madrid; 2012.

[11] Kim J, Stanton J, MacRae G. Effect of beam growth on reinforced concrete frames. J Struct Eng 2004; 130(9).

[12] Pérez A, Corres H, Giraldo A, Peset J. Cracking of RC members revisited. Influence of cover, fi/rho and stirrup spacing. An experimental and theoretical study. Structural concrete; 2013.

[13] FIB, Model Code 2010 - Final draft (bulletins 65 and 66); 2012.

[14] CEN, ENV1990-0: Eurocode 0 - Basis of structural design; 2002.

[15] Petschke T. Estudio analítico y experimental de los efectos de las deformaciones impuestas en las estructuras integrales. PhD thesis, Polytechnic University of Madrid; 2010.

[16] Marí AR, Bairán JM, Duarte N. Long-term deflections ins cracked reinforced concrete flexural member. Eng Struct 2011;32(3).

[17] Gribniak V, Klaklauskas G, Kliukas R, Jakubavskis R. Shrinkage effect on shortterm behaviour of reinforced concrete - when it should not be neglected. Mater Des 2013:51.

[18] Pérez A (coordinator). M-22 Proyecto de estructuras frente a los efectos de las deformaciones impuestas. Asociación científico-técnica del hormigón estructural. Monografía $n^{\circ} 22$. Madrid, Spain; 2012.

[19] CEN, EN 1992-1-1: Eurocode 2 - Design of concrete structures - Part 1-1: General rules and rules for buildings; 2004.

[20] Ministerio de Fomento. CTE DB-Código Técnico de la Edificación. Documento Básico Acciones en la Edificación. Madrid, Spain; April 2003.

[21] AFNOR. DTU P18-702 BAEL 91 (revises 99). Règles techniques de conception et de calcul des ouvrages et constructions en béton armé suivant la méthode des états limites. Fascicule 62, titre 1er du CCTG - Travaux section 1:béton armê; February 2000 . 